\title{
Non-pharmacological intervention for memory decline
}

\author{
Maria Cotelli ${ }^{1}{ }^{*}$, Rosa Manenti $^{1}$, Orazio Zanetti ${ }^{1}$ and Carlo Miniussi ${ }^{1,2}$ \\ IRCCS Centro San Giovanni di Dio Fatebenefratelli, Brescia, Italy \\ ${ }^{2}$ Department of Biomedical Sciences and Biotechnologies, National Neuroscience Institute, University of Brescia, Brescia, Italy
}

Edited by:

Simone Rossi, Azienda ospedalira

Universitaria Senese, Italy

\section{Reviewed by:}

Leonardo Cohen, National Institutes of Health, USA

Paolo M. Rossini, University Campus

Bio-Medico, Italy

\section{*Correspondence:}

Maria Cotelli, IRCCS Centro San Giovanni di Dio Fatebenefratelli, Via Pilastroni 4, 25125 Brescia, Italy. e-mail: mcotelli@fatebenefratelli.it

\begin{abstract}
Non-pharmacological intervention of memory difficulties in healthy older adults, as well as those with brain damage and neurodegenerative disorders, has gained much attention in recent years. The two main reasons that explain this growing interest in memory rehabilitation are the limited efficacy of current drug therapies and the plasticity of the human central nervous and the discovery that during aging, the connections in the brain are not fixed but retain the capacity to change with learning. Moreover, several studies have reported enhanced cognitive performance in patients with neurological disease, following non-invasive brain stimulation [i.e., repetitive transcranial magnetic stimulation and transcranial direct current stimulation to specific cortical areas]. The present review provides an overview of memory rehabilitation in individuals with mild cognitive impairment and in patients with Alzheimer's disease with particular regard to cognitive rehabilitation interventions focused on memory and non-invasive brain stimulation. Reviewed data suggest that in patients with memory deficits, memory intervention therapy could lead to performance improvements in memory, nevertheless further studies need to be conducted in order to establish the real value of this approach.
\end{abstract}

Keywords: training, Alzheimer, $\mathrm{MCl}$, aging, brain stimulation
Memory is the ability to store, maintain, and retrieve information from the mind. In other words, it is the human ability to construct a virtual bridge between the past, the present, and the future.

Memory declines with physiological aging, and memory loss is characteristic of several clinical conditions such as mild cognitive impairment (MCI) and Alzheimer's disease (AD). Nonpharmacological interventions for memory difficulties in healthy older adults, as well as those with brain damage and neurodegenerative disorders, have gained much attention in recent years (Ball et al., 2002; Willis et al., 2006; Acevedo and Loewenstein, 2007). The limited efficacy of the current drug therapies and the recent advances of knowledge in the field of human central nervous system plasticity are two of the main reasons for the growing interest in rehabilitation (Landi and Rossini, 2010; Buschert et al., 2011). The ability to learn and remember new information declines with physiological aging (Grady and Craik, 2000). In particular, older adults show impairments in episodic memory tasks (Tulving, 1983), which involve encoding and retrieving information from previously experienced events. These reductions in cognitive performance most likely reflect age-related changes in the brain, which undergoes significant structural and functional modifications during the aging process (Creasey and Rapoport, 1985). These modifications may be due to decreased cell metabolism, which is characterized by a reduced activity of networks dedicated to carrying out a given function.

Due to the rapidly aging demographic, the mean age of the general population is increasing, with a corresponding increase in the number of people that will develop cognitive disabilities related to aging. Therefore, it is extremely important to identify effective interventions to reduce the incidence of these disabilities in older adults. Interestingly, memory functions in some older subjects are able to compensate for the structural losses that occur during aging; these individuals show performance improvements comparable to those of young subjects. Accordingly, understanding the basis of minor vs. major age-related cognitive declines is of great interest.

Several imaging studies have addressed the neural mechanisms underlying memory decline in older adults (Grady et al., 1995, 1998; Schacter et al., 1996; Cabeza et al., 1997, 2000; Rosen et al., 2002; Gutchess et al., 2005; Dennis et al., 2008). Based on these age-related changes, an amendment to the hemispherical encoding retrieval asymmetry (HERA) theory (Tulving et al., 1994) was proposed for older adults. The HERA model predicts that the left prefrontal cortex (PFC) specializes in encoding while the right PFC specializes in retrieval. Accordingly, functional magnetic resonance imaging (fMRI) studies in older adults led to a proposal of the hemispheric asymmetry reduction in older adults (HAROLD) model (Cabeza, 2002). Although activation of the right PFC during retrieval was less pronounced, bilateral involvement of the PFC during both encoding and retrieval was observed in healthy elders, which differed from young participants who exhibited only left hemisphere activity during retrieval tasks. Overall, the significance of these changes is intriguing because they could be caused either by an effective functional compensation strategy or by inadequate and/or less efficient processing in the contralateral hemisphere.

Despite numerous studies on the role of the dorsolateral PFC (DLPFC) in episodic memory, neuroimaging studies have demonstrated the involvement of a distributed neural network constituted by the DLPFCs, the medial temporal lobes, the parietal cortices (PARCs), and the precuneus (Wagner et al., 1998; Rugg 
and Wilding, 2000; Buckner et al., 2001; Fletcher and Henson, 2001; Cabeza and Nyberg, 2003; Cabeza et al., 2003; Simons and Spiers, 2003).

Recently, repetitive transcranial magnetic stimulation (rTMS) has been used to investigate prefrontal asymmetry in healthy aging individuals (Rossi et al., 2004), thereby confirming the reduction in asymmetry previously shown by fMRI (Cabeza, 2002). Moreover, a recent brain stimulation study showed that older adults with higher memory performance showed less prefrontal asymmetry, which has led to the hypothesis that decreased asymmetry could represent an efficient strategy for counteracting age-related memory decline (Manenti et al., 2011). In line with these data, several studies have suggested that cerebral plasticity and cognitive reserves play important roles in physiological aging and rehabilitation (Stern, 2002, 2006; Stern et al., 2005; Valenzuela and Sachdev, 2006, 2009; Noack et al., 2009).

Many researchers are interested in helping older adults maintain their cognitive abilities and quality of life (Fratiglioni et al., 2004; Salthouse, 2006; Willis and Schaie, 1986; Rasmusson et al., 1999; Ball et al., 2002; Salthouse, 2006; Willis et al., 2006; Craik et al., 2007; Lovden et al., 2010, for a review see Tardif and Simard, 2011).

The advanced cognitive training for independent and vital elderly (ACTIVE) study was a multicentre, randomized, controlled trial conducted by Ball et al. (2002) that examined the long-term outcomes of cognitive interventions in older individuals who were living independently. This work showed that each of the three cognitive interventions used in the trial improved the cognitive ability of older individuals and that these improvements were maintained throughout the following 2 years of follow-up. Subsequently, Willis et al. (2006) confirmed that cognitive training improved cognitive functions in well-functioning older adults and that the improvement lasted for up to 5 years from the beginning of the intervention. In addition, this trial provided some evidence that improvements in cognitive function can have a positive effect on daily living skills. Moreover, recent multisite, randomized, controlled, double-blind studies have confirmed the positive effects resulting from computerized cognitive training programs on memory and attention in older adults (Smith et al., 2009; Zelinski et al., 2011).

A systematic review of the literature conducted by Zehnder et al. (2009) demonstrated significant improvements for specific memory tasks (paired associate learning and immediate and delayed recall) as a result of training effects. However, the authors concluded that the evidence supporting the effectiveness and specificity of training intervention is scarce. Is it possible to develop prosthetics to correct poor memory, equivalent to spectacles for poor vision? The present review provides an overview of rehabilitation programs focusing on memory improvement for individuals with MCI and patients with AD. Particular emphasis is placed on cognitive rehabilitation interventions focused on episodic memory, as well as the application of non-invasive brain stimulation techniques such as rTMS and transcranial direct current stimulation (tDCS) to improve memory performance.

In regard to the application of cognitive rehabilitation, we divided interventions into the following four principal approaches: (a) memory exercises, (b) teaching memory strategies, (c) procedural memory, and (d) errorless learning techniques.

The aim is to highlight the most important aspects of these rehabilitation approaches and to suggest the opportunity of combining a cognitive rehabilitation intervention with non-invasive brain stimulation to increase the effectiveness of intervention.

\section{MEMORY INTERVENTIONS IN MILD COGNITIVE IMPAIRMENT AND ALZHEIMER'S DISEASE}

Studies on normal subjects (young and elderly participants) and on patients affected by neurological disease have shown that the improvement and recovery of function after cerebral deficits or environmental changes could involve a reorganization of the central nervous system. Functional neuroimaging studies have shown that cerebral reorganization occurs after rehabilitation interventions (Warburton et al., 1999; Nyberg et al., 2003; Shaywitz et al., 2003; Strangman et al., 2005).

Importantly, previous studies on healthy aging have focused on prevention; this concept is even more relevant if we apply it to a particular elderly adult population afflicted with MCI or more specifically, amnesic MCI (aMCI; Petersen, 2004). MCI is widely used to define a disorder among individuals who have subjective cognitive deficits, objective memory impairments, or other cognitive deficits without impairments in daily activities (Petersen et al., 1999). Given the increased risk of developing AD in this population, there is a strong argument for developing cognitive interventions aimed at reducing memory difficulties in MCI patients. A recent review of cognitive intervention strategies for MCI patients indicated that memory impairment might be best targeted by interventions that develop compensatory strategies and induce the learning of specific information relevant to the affected individual (Stott and Spector, 2011).

Along these lines, several studies have utilized cognitive training aimed at improving memory in MCI patients (Table $\mathbf{1}$ ).

Using computer-assisted cognitive training for agingassociated memory deficits, Gunther et al. (2003) found significant improvements in short- and long-term memory for verbal and visual stimuli. Cipriani et al. (2006) evaluated a computer-based cognitive training program in $\mathrm{AD}$ patients compared with patients affected by MCI, as well as a control group of patients with the diagnosis of multiple system atrophy (MSA). The computerbased cognitive training included exercises designed to stimulate the learning of new information and exercises involving information retrieval from semantic memory. The MCI participants showed a significant improvement in working memory tasks, psychomotor learning, and behavioral memory. In contrast, the $\mathrm{AD}$ patients improved in global cognitive status (MMSE), verbal fluency and executive functions. The MSA patients did not benefit from cognitive training. Importantly, this study indicated a general beneficial effect of the training because participants not only improved in computer-based trained exercises but also in cognitive tests (Cipriani et al., 2006).

Furthermore, computer-based cognitive training has been shown to lead to cognitive and mood benefits in MCI individuals treated with cholinesterase inhibitors (ChEIs; Rozzini et al. 2007). In this study, the authors evaluated the efficacy of computerbased cognitive training that included several exercises designed 


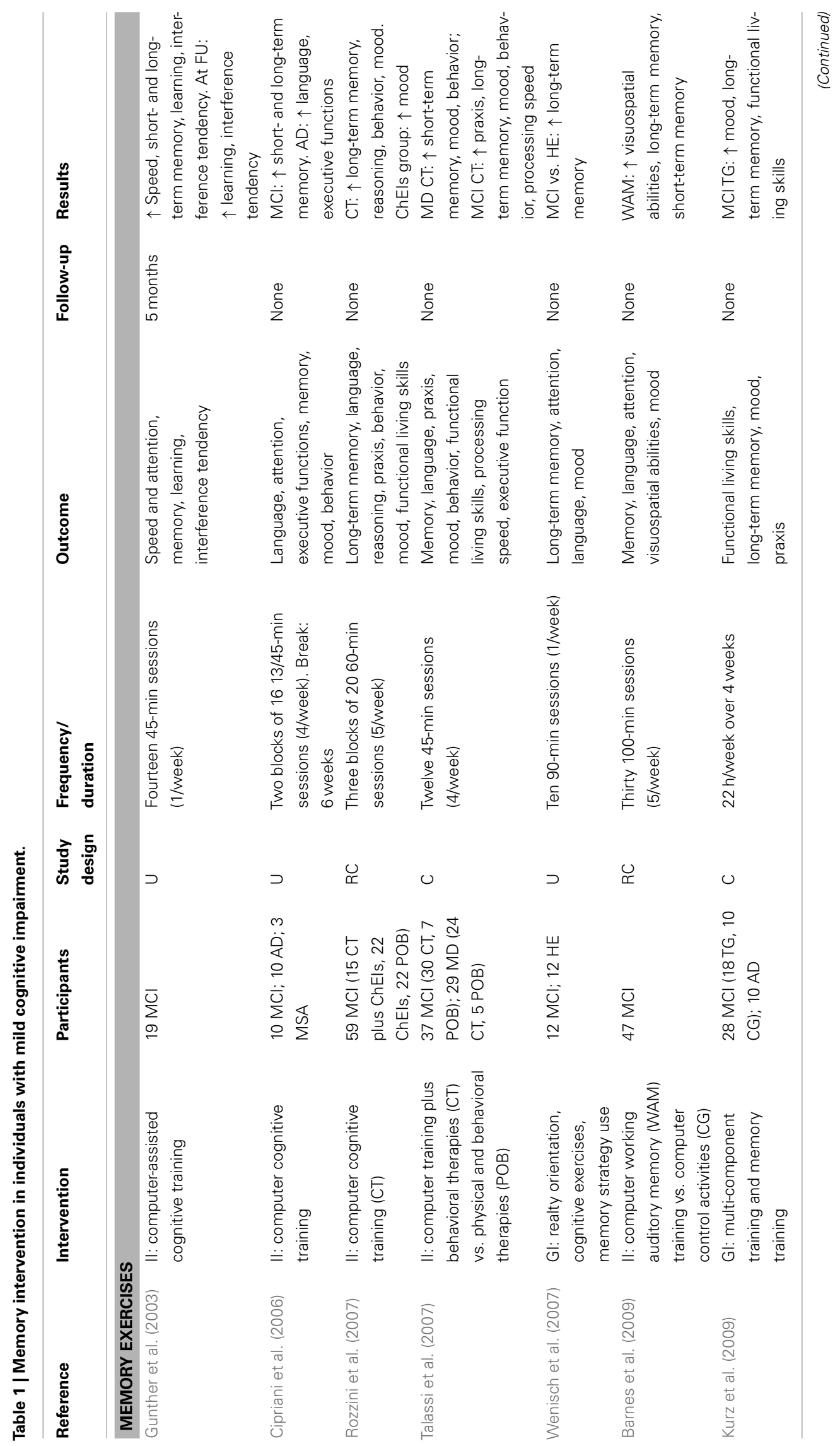




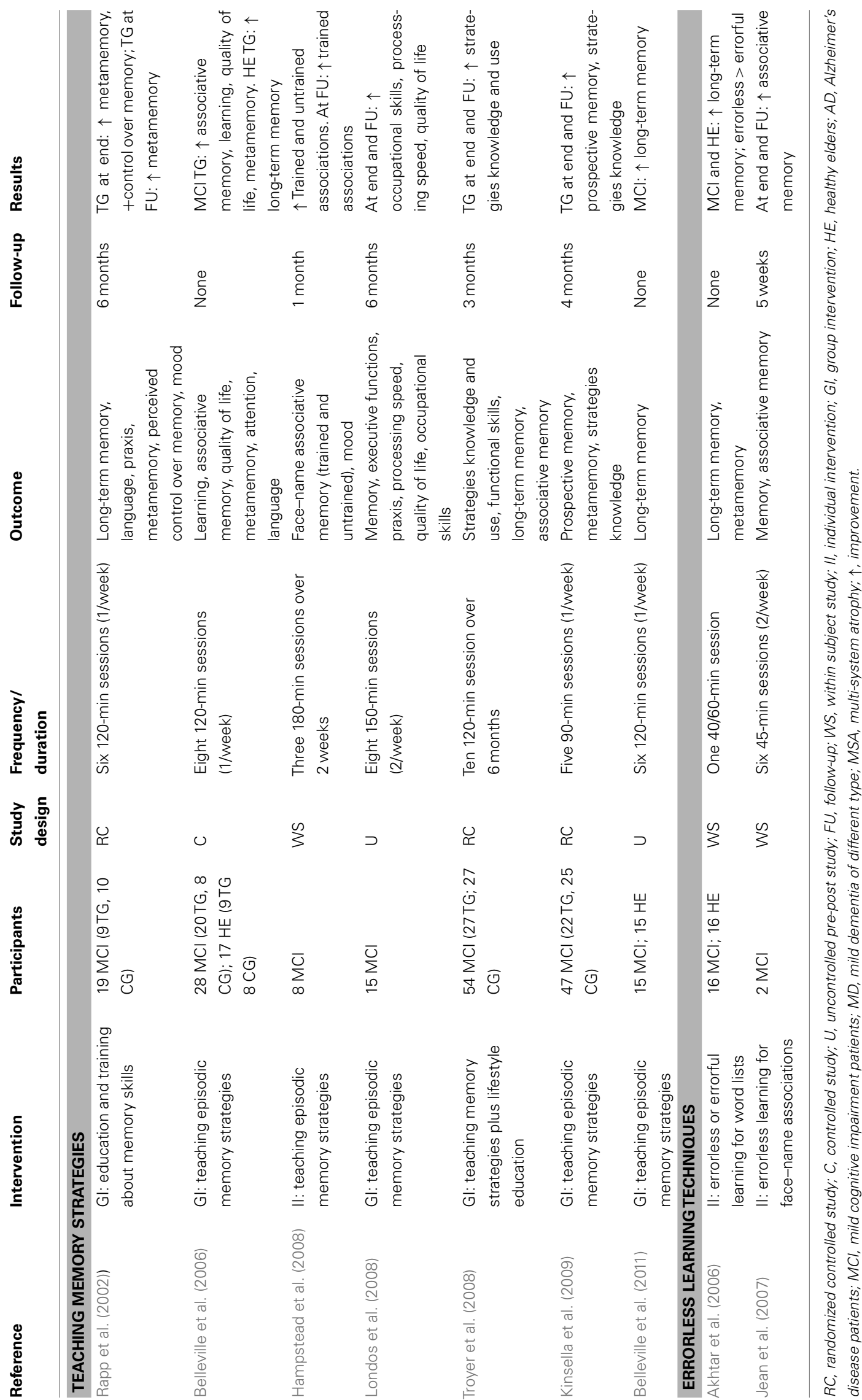


to stimulate memory, attention, language, abstract reasoning and visuospatial abilities in MCI patients who were either treated or not treated with ChEIs. The results showed that MCI individuals without any treatment were stable in cognitive, functional and behavioral status after 1 year while MCI patients treated only with ChEIs improved in depressive symptoms. However, individuals treated with cognitive training and ChEIs showed improvements in two different cognitive areas (memory and abstract reasoning), as well as in depressive symptoms. Talassi et al. (2007) compared the effectiveness of the cognitive training protocol used by Rozzini et al. (2007) plus occupational and behavioral therapies with that of physical rehabilitation plus occupational and behavioral therapies. They tested MCI and mild dementia (predominantly $\mathrm{AD}$ ) patients. The study demonstrated that only computer-based training plus occupational and behavioral therapies provided an improvement in the cognitive and affective status of individuals with MCI and dementia. In contrast, a rehabilitation program that did not stimulate cognitive function did not have significant effects (Talassi et al., 2007). Similarity, a randomized, controlled pilot trial of intensive, computer-based cognitive training concluded that this intervention was effective in subjects with MCI (Barnes et al., 2009).

Using multi-component cognitive training that included memory exercises, Kurz et al. (2009) showed improved episodic memory measures in MCI individuals (California Verbal Learning Test and Rey Complex Figure Recall Test), as well as increases in daily living activities and mood. Furthermore, Wenisch et al. (2007) showed that programs that included memory exercises resulted in an improvement of associative memory abilities in MCI and normal subjects (although a greater improvement was observed in MCI cases).

Several studies have investigated the effect of training in the use of memory strategies on individuals with MCI, showing prospective memory (Kinsella et al., 2009), quality of life (Londos et al., 2008) and metamemory (Rapp et al., 2002) improvements. A randomized controlled trial for individuals with aMCI explored the efficacy of a memory intervention as measured by the acquisition and application of everyday memory strategies (Troyer et al., 2008). This study found an improvement after the use of memory strategies. Another relevant study, conducted by Belleville et al. (2006), aimed to assess the efficacy of a 2-month, multifactorial cognitive training protocol designed to teach episodic memory strategies in individuals with MCI. The study included healthy elderly and MCI individuals. The training was comprised of episodic memory strategy training, meta-cognition, and computer-based training of attention. The authors found a significant effect on episodic memory tests (delayed list recall and face-name association) in both the control and MCI participants (Belleville et al., 2006).

Moreover, studies using errorless learning techniques for subjects with MCI have shown that this approach can facilitate the learning of information and associations (Akhtar et al., 2006; Jean et al., 2007). This technique refers to a learning condition in which patients are prevented from making errors. Baddeley and Wilson (1994) demonstrated that amnesic patients learn better under errorless conditions. This principle has proven successful over a range of tasks, including learning word lists (Hunkin et al., 1998a), person and object names (Wilson et al., 1994; Parkin et al., 1998; Evans et al., 2000), word processing skills (Hunkin et al., 1998a), semantic concepts (McKenna and Gerhand, 2002), word pair associations (Squires et al., 1997), and electronic diary programming (Wilson et al., 1994). The general principles of errorless learning incorporate specific techniques for vanishing cues and spaced retrieval (Landauer and Bjork, 1978; Glisky et al., 1986; Glisky, 1992; Camp et al., 1993, 1996). In general, the method of vanishing cues involves the gradual addition and then reduction of cues across learning trials, whereas the spaced retrieval method requires the recall of the target item after short but gradually increased intervals.

The use of these methods in MCI individuals led to an improvement in associative memory (Jean et al., 2007) and word list recall (Akhtar et al., 2006), which supports the effectiveness of these techniques in patients with memory deficits.

Recently, studies have been conducted using functional imaging techniques to examine how brain activity changes in response to cognitive training programs with MCI participants. In a study conducted by Hampstead et al. (2011), fMRI was used to test whether there were training-specific changes in the activation and connectivity within memory-related areas of patients with multidomain MCI. The findings suggested that the effectiveness of explicit memory strategy training in subjects with MCI (associative memory) is associated with training-specific increases in activation and connectivity across a distributed neural system, which included areas involved in explicit memory function.

The significant neural activity changes observed after explicit memory strategy training in MCI and healthy participants were confirmed in a recent fMRI study (Belleville et al., 2011). This study demonstrated increased brain activation after training that correlated with increased performance in long-term episodic memory abilities. The activations included a large network involving the frontal, temporal, and parietal areas (Belleville et al., 2011). These data provide empirical support for the use of cognitive training as an intervention for individuals with MCI.

The main limitation of these studies is the heterogeneity of the target population. MCI is a controversial label describing a range of age-related intellectual declines that includes people presenting with and without a dementia prodrome state (Schneider, 2005; Gauthier et al., 2006; Visser et al., 2006; Whitehouse and Brodaty, 2006; Chertkow et al., 2007; Whitehouse, 2007). Moreover, the use of different types of interventions and different outcome measures makes direct comparisons difficult (Stott and Spector, 2011). Nevertheless, the results of these studies highlight the value of prevention in the older adult population.

Memory problems are typically one of the first warning signs of cognitive decline in $\mathrm{AD}$. $\mathrm{AD}$ is the most common cause of dementia and results in a slow and progressive loss of memory, language, reasoning, and other cognitive functions, which eventually become completely impaired.

Behavioral and functional dysfunctions following AD constitute some of the major causes of disability worldwide and have a significant impact on the lives of the affected individuals and their families. However, this process is not an "all or none" phenomenon. Importantly, during the first stage of the disease process, some cognitive functions are preserved (i.e., procedural memory) and can 
be the target of cognitive interventions (Beck et al., 1988; Zanetti et al., 1998, 2001, 2002; Clare et al., 2001; De Vreese et al., 2001; Olazaran et al., 2004, 2010; Onder et al., 2005; Souchay et al., 2008). Moreover, several studies have demonstrated at least a modest benefit from specific interventions designed to improve functioning in select cognitive tasks.

The application of cognitive rehabilitation during early dementia is based on evidence regarding the neuropsychological profile of patients with $\mathrm{AD}$. $\mathrm{AD}$ patients show short-term forgetfulness, whereas long-term memory and implicit memory appear to be relatively unaffected (Perry and Hodges, 1996). These patients exhibit a profound impairment in episodic memory, as demonstrated by free recall and recognition tests, especially after delays (Greene et al., 1996). Moreover, episodic memory difficulties in AD patients are primarily the result of defective information encoding and storage (Kopelman, 1985).

Despite the memory deficits associated with $\mathrm{AD}$, the facilitation of episodic memory can be used when adequate support is provided (Backman and Dixon, 1992; Backman, 1996).

Plasticity mechanisms also play a role in $\mathrm{AD}$. In patients with $\mathrm{AD}$, an increase in the activation of areas involved in memory, or a recruitment of new areas, has been shown (Becker et al., 1996; Woodard et al., 1998; Backman et al., 1999). However, cognitive rehabilitation and cognitive training focusing on memory functioning in dementia patients remain somewhat controversial. A recent Cochrane Library report (Clare et al., 2003b) suggested that the present findings do not provide a strong rationale for the application of cognitive training interventions for people with early-stage $\mathrm{AD}$ or vascular dementia. These conclusions must be viewed with caution due to the limited number of randomized controlled trials evaluating the individual cognitive rehabilitation approaches available and the associated methodological limitations. To date, it is not possible to draw conclusions about the efficacy of such interventions for people with early-stage dementia (Clare et al., 2003b).

Nevertheless, several studies have demonstrated benefits from specific interventions designed to improve functioning on select cognitive tasks (Table 2). For example, Cahn-Weiner et al. (2003) suggested that $\mathrm{AD}$ patients who are taught specific memory strategies (i.e., memory training to learn word lists) can benefit at least modestly, even if non-significantly, from training exercises.

The main cognitive methods used in $\mathrm{AD}$ rehabilitation include procedural memory training and errorless learning techniques. Neuropsychology findings have suggested that, especially during the first stages of the disease, relatively well preserved skills should be the target of rehabilitative interventions that are aimed at delaying the decline of cognitive functioning. There is evidence that procedural memory, which involves the cognitive use of previous experiences without recognition, is relatively well preserved in AD. Following this evidence, a study conducted by Zanetti et al. (2001) confirmed the effectiveness of procedural memory training consisting of three consecutive weeks in 13 basic and instrumental activities of daily living in mild and mild-to-moderate $\mathrm{AD}$ patients. The trained group, in comparison to an untrained group, showed a significant reduction in the time needed to perform these activities, whereas the control group showed a non-significant increase (Zanetti et al., 2001).
Similarly, results from Farina et al. (2002) provide further support for the stimulation of procedural memory. In their first study, the authors compared the stimulation of procedural memory with the training of partially spared cognitive functions. Their findings demonstrated that both training exercises induced a substantial improvement in everyday functioning, even if the results of cognitive tests suggested that the training of procedural memory may have been more effective (Farina et al., 2002). In a subsequent study, Farina et al. (2006) compared the effect of recreational activities with gains induced by specific cognitive programs (i.e., procedural memory training vs. neuropsychological rehabilitation of "residual functions"). These results showed that AD patients exposed to recreational activities reported a significant improvement in behavioral disturbances, memory, and functional living skills, as well as reduced caregiver distress at the 6-month followup. However, this study did not show improvements as a result of cognitive-specific intervention (Farina et al., 2006), thus highlighting that the benefits from this therapy were usually confined to the treatment period and that there was a rapid loss of improvement after the end of training.

A different method is applied for the treatment of memory in $\mathrm{AD}$ patients during errorless learning because some previous studies have suggested that cognitive rehabilitation approaches may have positive effects on memory functioning during the earlystages of AD (Backman and Dixon, 1992; Backman, 1996; Clare et al., 1999, 2000, 2001, 2002, 2003a, 2009). This technique employs learning conditions in which patients are prevented from making errors and is based on various techniques (e.g., vanishing cues and spaced retrieval) that have been previously described for MCI studies. In particular, Clare and collaborators used a combination of methods to successfully produce long-lasting memories for a specific set of face-name pairs (Clare et al., 1999, 2000, 2001, 2002, 2003a). Furthermore, a single case study by Winter and Hunkin (1999) provided descriptive evidence that errorless learning in $\mathrm{AD}$ may lead to better re-learning of familiar names compared to learning with errors. Davis et al. (2001) evaluated a 5-week cognitive intervention using training in face-name associations, spaced retrieval, and cognitive stimulation in a group of $\mathrm{AD}$ patients. In this study, the patients were randomly assigned to either a cognitive or placebo intervention. Although the patients in the intervention group showed improvements in face-name information and in a measure of attention, the beneficial results did not extend to additional neuropsychological measures or caregiver-rated patient quality of life.

A single case study by Clare et al. (1999; Clare et al., 2003a) tested the hypothesis that a patient in the early-stages of $\mathrm{AD}$ can learn face-name associations by applying errorless learning techniques. The results of the study showed a striking improvement in a patient's recall of the face-name association that was maintained up to 9 months after the end of the study. Subsequent studies demonstrated that improvements in patient recall remained relatively stable over the following year, and the patient's performance on the trained items remained well above baseline levels even after 2 years (Clare et al., 2001). The same authors confirmed an improvement in face-name memory in six individuals with AD (Clare et al., 2000). These interesting findings were extended in a controlled trial that involved 12 participants with $\mathrm{AD}$ 


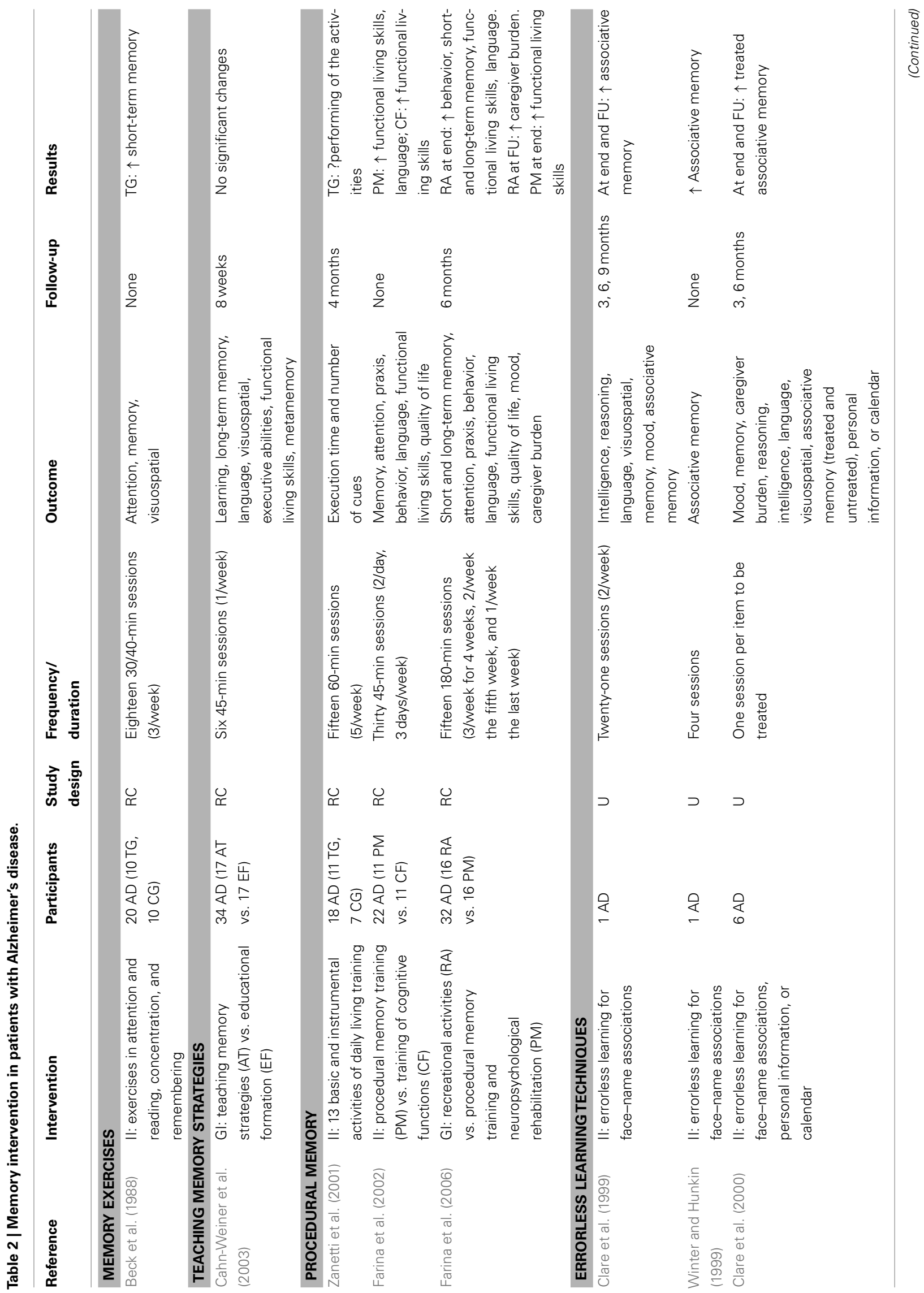



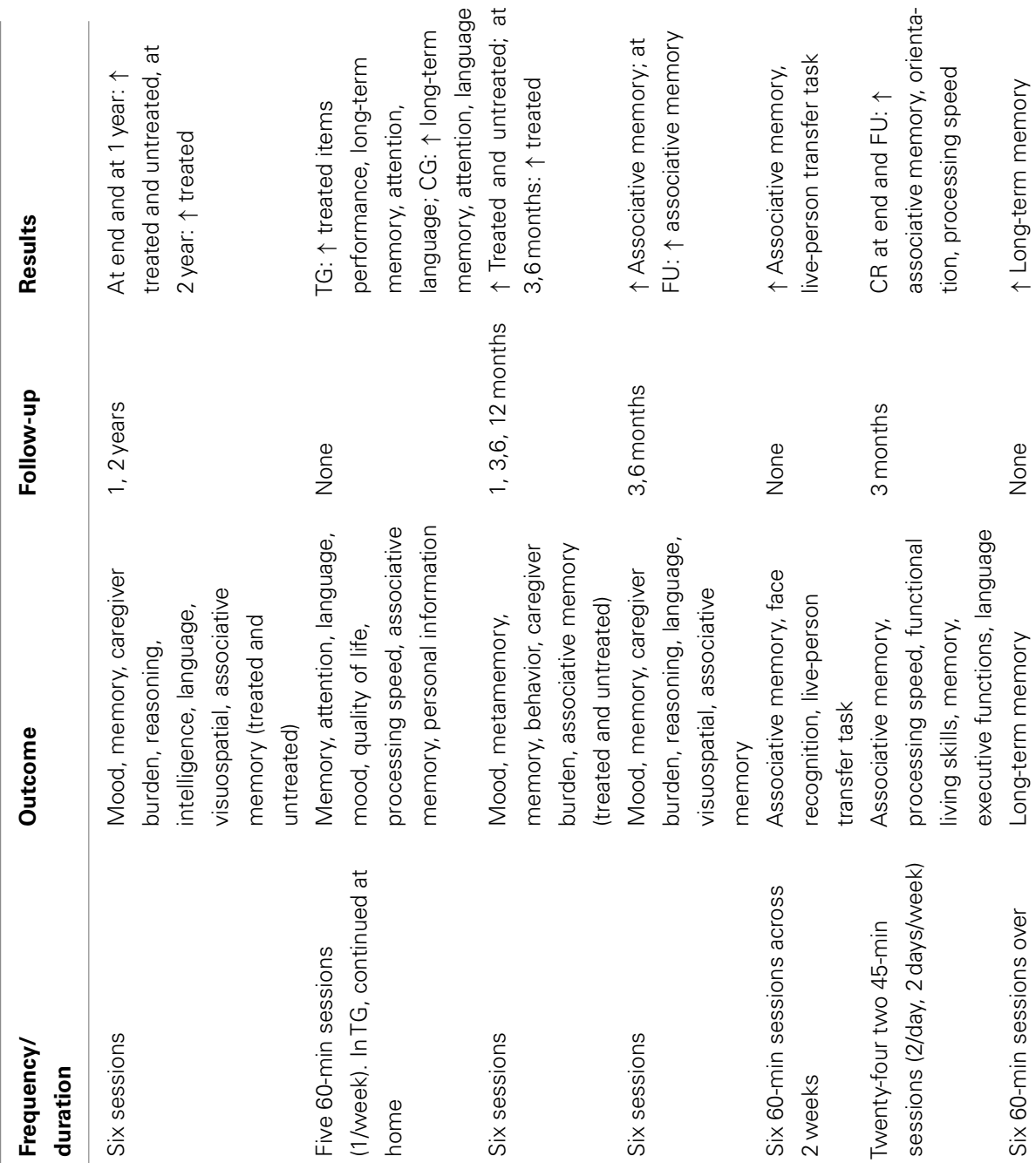

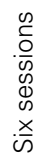
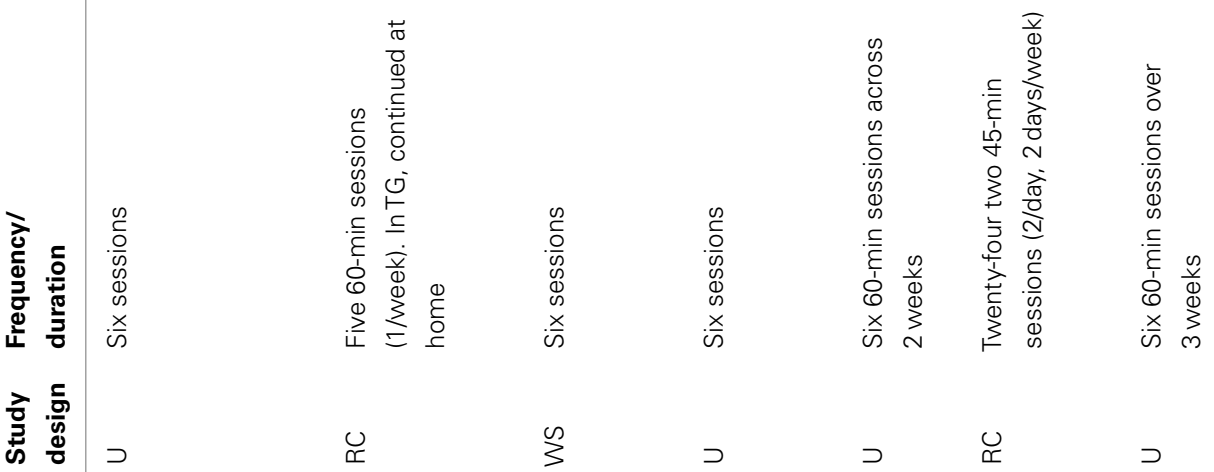

$\stackrel{\cup}{\simeq}$

出

$\supset$

$\supset \quad \stackrel{\Upsilon}{\Upsilon}$

$\begin{array}{ll}\stackrel{0}{\circ} \\ \stackrel{0}{=} \\ \stackrel{0}{0} \\ \stackrel{0}{5} \\ \text { m } & \infty\end{array}$

$\stackrel{?}{\stackrel{2}{ }}$
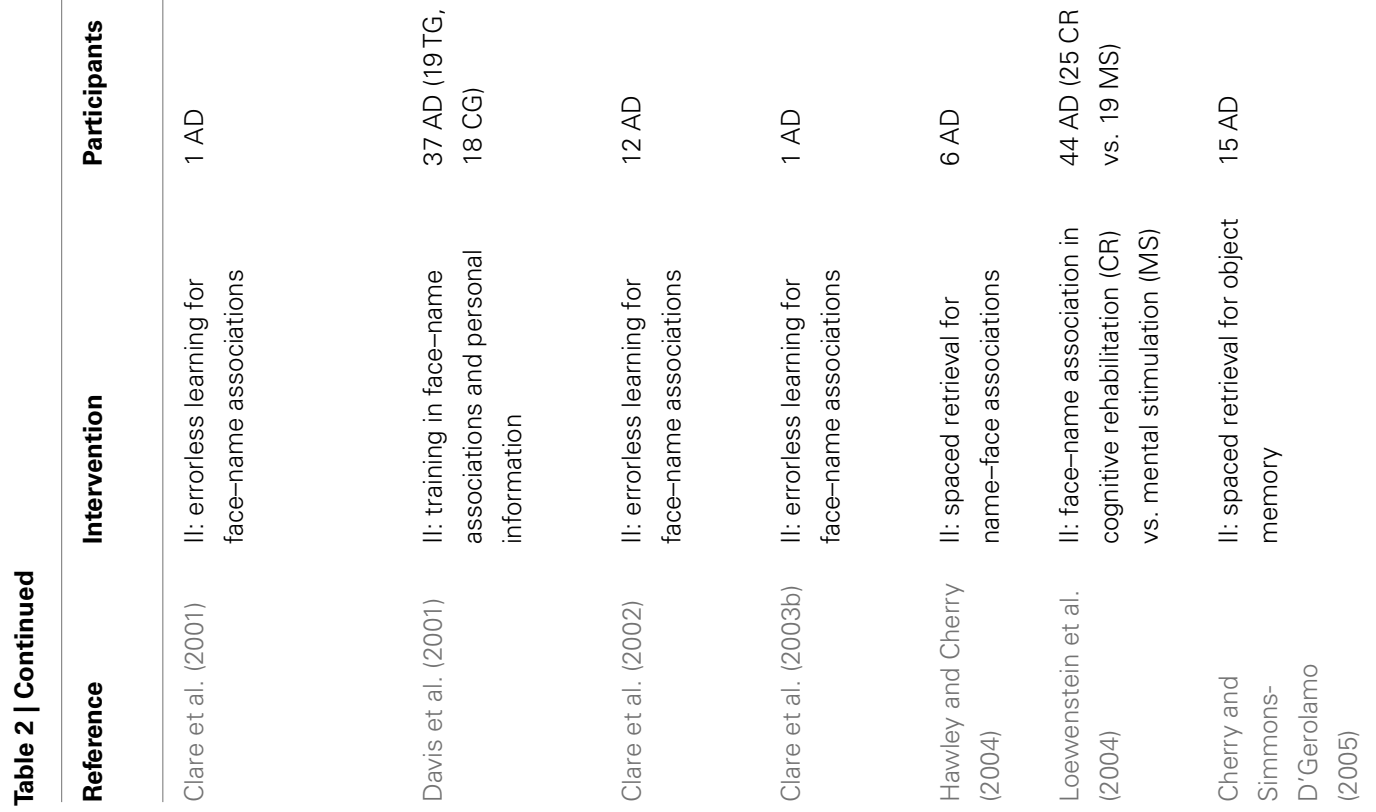


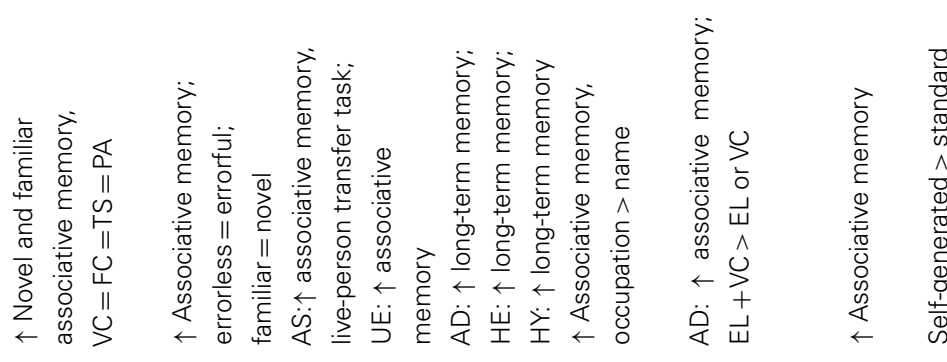

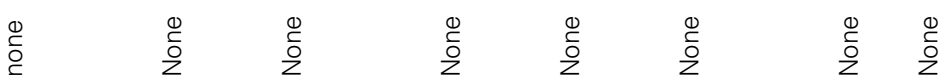
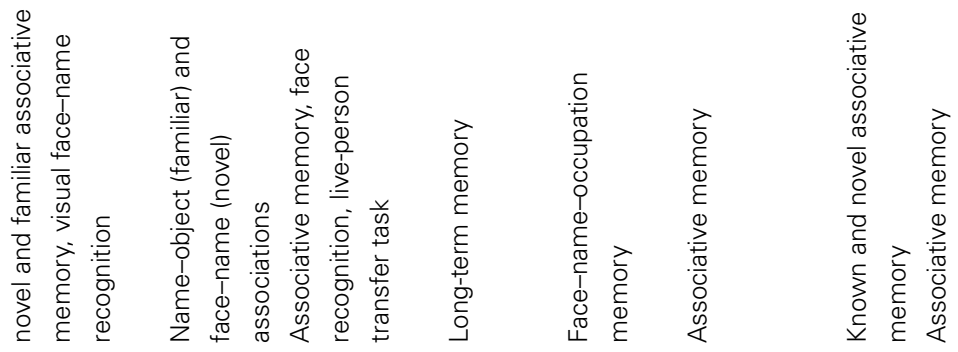

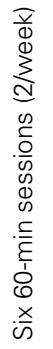
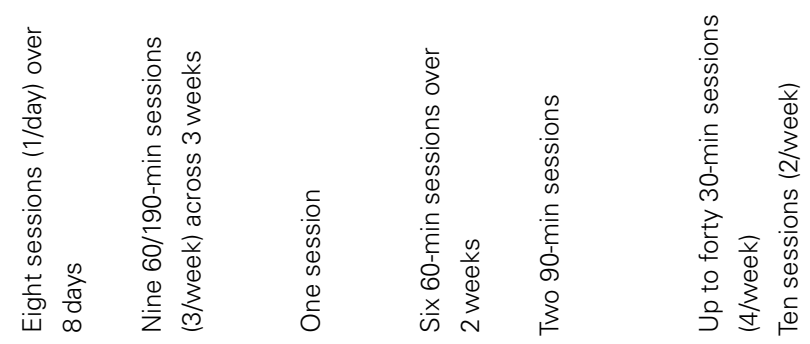

s

皮

๖

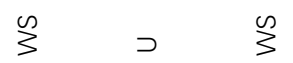

3

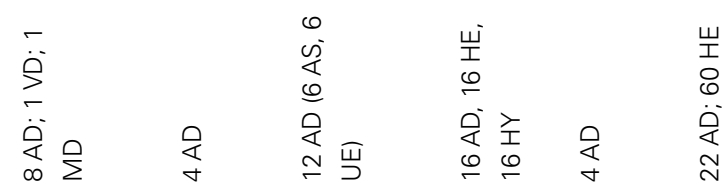

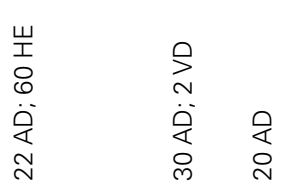
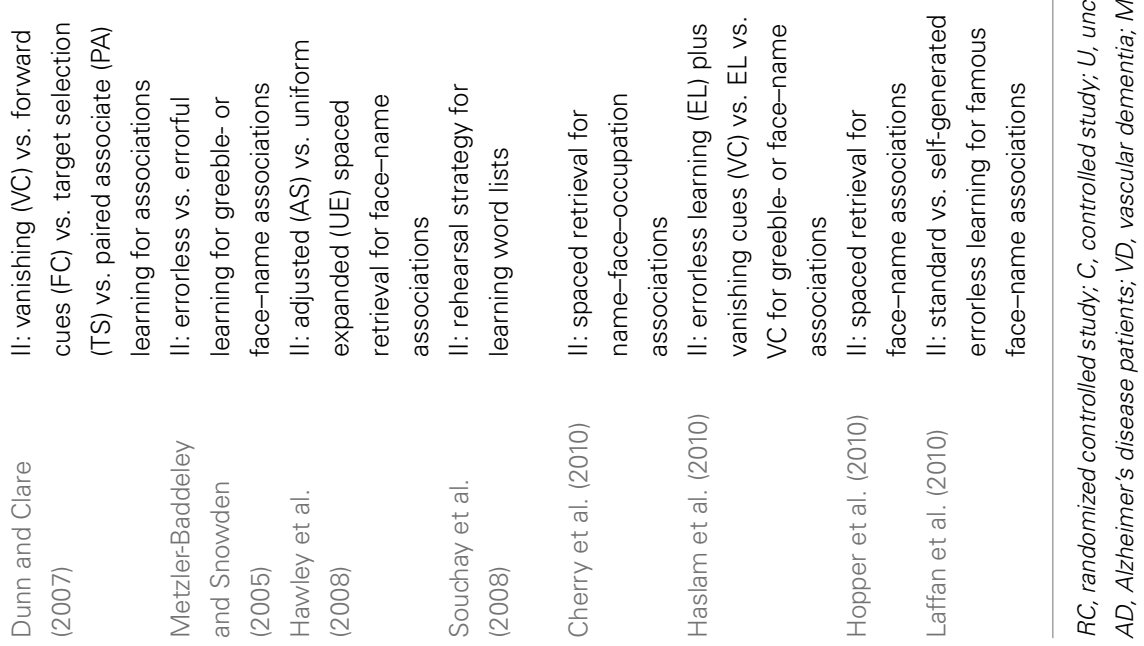
(Clare et al., 2002) in which a significant recall improvement was obtained for trained face-name associations but not for control items (i.e., untreated items). Interestingly, the gains were maintained for 6 months after rehabilitation (for a review see Werheid and Clare, 2007). These findings are consistent with the literature demonstrating that errorless learning is more effective than learning with error among other patient populations (Squires et al., 1997; Hunkin et al., 1998b; Tailby and Haslam, 2003).

Dunn and Clare (2007) conducted a study comparing the effects of four different learning techniques (vanishing cues, forward cues, target selection, and paired associate learning) on the acquisition of name-face associations among patients in the earlystage of $\mathrm{AD}$, patients with vascular dementia and patients with mixed dementia. Overall, these findings showed that each learning method was effective and provided further evidence that learning is possible in $\mathrm{AD}$ and vascular dementia patients, which had been shown in previous studies (Camp et al., 1993; Bird and Kinsella, 1996). In addition, several other studies have investigated the usefulness of errorless learning for memory training in $\mathrm{AD}$, which demonstrated improvements in memory for associations and compared the efficacy of different errorless learning methods (Clare and Wilson, 2004; Metzler-Baddeley and Snowden, 2005; Haslam et al., 2010; Laffan et al., 2010; Thom and Clare, 2011).

Another promising intervention for helping individuals with $\mathrm{AD}$ during learning is the use of spaced retrieval training (SRT). In SRT exercises, the subject is asked to repeatedly recall a target after increasingly longer intervals of time. This technique is based on the method of expanding retrieval abilities originally described by Landauer and Bjork (1978). Camp and Stevens (1990) adapted the original procedure and applied it to patients with $\mathrm{AD}$. In this form, the intervals were adjusted according to the patient's performance. Several studies have demonstrated that adjusted SRT is efficacious in individuals with probable $\mathrm{AD}$ and leads to an improvement in associative memory (Hawley and Cherry, 2004; Cherry and Simmons-D'Gerolamo, 2005; Hopper et al., 2005, 2010; Hawley et al., 2008; Cherry et al., 2010).

Finally, Loewenstein et al. (2004) combined specific cognitive techniques (spaced retrieval, dual cognitive support, procedural memory activation, visuo-motor processing, and functional skills training) into a single cognitive rehabilitation treatment for mildly impaired AD patients. The results of this study indicated that $\mathrm{AD}$ patients benefited from cognitive rehabilitation intervention and demonstrated improvements in the learning of face-name associations, processing speed, functional abilities, and orientation.

Because cognitive rehabilitation and cognitive training focusing on memory functioning in dementia patients remain somewhat controversial, the recent Cochrane Library report (Clare et al., 2003b) suggests that the present findings do not provide a strong rationale for the application of cognitive training interventions for people with early-stage $\mathrm{AD}$ or vascular dementia and that well-designed trials would help provide more definitive evidence.

Based on the literature, a cognitive rehabilitation approach focusing on individualized, personally meaningful goals that combine errorless learning with a number of other memory techniques seems to be a promising strategy for patients with $\mathrm{AD}$ (Cotelli et al., 2006, 2011c).

\section{NON-INVASIVE BRAIN STIMULATION TO IMPROVE EPISODIC MEMORY IN MCI AND AD PATIENTS}

Episodic memory and encoding and retrieval processes have been linked to different networks. Specifically, lesion and functional imaging studies have indicated that episodic memory involves a widespread network of brain structures, including the PFC and PARCs (Cabeza et al., 2008). In elderly subjects, successful memory encoding, and retrieval are associated with activation of the left inferior parietal lobules (IPLs) and the anterior hippocampus (Kircher et al., 2008).

In healthy participants, rTMS studies have confirmed the role of the PFC during the encoding and retrieval of verbal or nonverbal material (Rossi et al., 2001; Sandrini et al., 2003; Manenti et al., 2010a). However, rTMS studies in posterior brain areas have not yet elucidated this mechanism. Previous studies have demonstrated the involvement of PARCs, which is in contrast to rTMS studies. In particular, Rossi et al. (2006) found that the activity of the intraparietal sulci, unlike that of the DLPFC, is not causally involved in the encoding and retrieval of visual scenes. However, by combining fMRI and rTMS, Manenti et al. (2010b) provided the first evidence of a causal role of not only the PFC but also PARCs during word retrieval. Recently, the use of non-invasive brain stimulation to study cognitive functions and dysfunctions in stroke and neurodegenerative patients has attracted much attention. Specifically, rTMS has been shown to transiently modulate neural excitability. Since the introduction of rTMS, it has become evident that the modulatory effects of cortical stimulation may outlast the immediate stimulation period, with effects from repeated sessions lasting for days and even weeks. Along these lines, the use of tDCS has also been shown to have potential for the treatment of neurological diseases (Miniussi et al., 2008; Boggio et al., 2011b; Cotelli et al., 2011b; Miniussi and Rossini, 2011; Miniussi and Vallar, 2011).

Non-invasive brain stimulation techniques for modulating cortical activity include TMS (Wassermann et al., 2008a) and tDCS (Nitsche et al., 2008). Both TMS and tDCS can transiently influence behavior by altering spontaneous neuronal activity (Wassermann et al., 2008a), which may have facilitatory or inhibitory effects.

TMS involves the delivery of a brief (shorter than $1 \mathrm{~ms}$ ) and powerful (approximately $2 \mathrm{~T}$ ) magnetic pulse to the scalp through a coil. The magnetic pulse induces a transitory electric current in the cortical surface under the coil, which causes the depolarization of cell membranes(Barker et al., 1985, 1987) and transynaptic depolarization of a population of cortical neurons (Wassermann et al., 2008b).

TMS initially involved the delivery of single magnetic pulses (Barker et al., 1985). In the nineties, it became possible to deliver trains of magnetic pulses with a rhythmic repetition rate of up to $100 \mathrm{~Hz}$. This has been referred as rTMS. Studies have shown that rTMS interacts with cortical activity in a repetition frequency-dependent manner. Empirical evidence has indicated that continuous rTMS below $1 \mathrm{~Hz}$ reduces cortical excitability, whereas intermittent rTMS trains above $5 \mathrm{~Hz}$ have the opposite effect (Pascual-Leone et al., 1994; Chen et al., 1997; Maeda et al., 2000). Therefore, rTMS allows for transient modulation of neural excitability. Changes last for several minutes beyond the 
end of stimulation, depending on the stimulation duration and parameters (see Rossi et al., 2009) for guidelines).

The tDCS technique (Priori, 2003; Nitsche et al., 2008) involves applying weak electrical currents $(\sim 0.5-2 \mathrm{~mA})$ directly to the head for several minutes ( $\sim 5-20 \mathrm{~min})$. These currents generate an electrical field that modulates neuronal activity according to the modality of the application. Neurons respond to tDCS by altering their firing rates. Several studies using animal models (Creutzfeldt et al., 1962; Bindman et al., 1964) have suggested that cathodal tDCS reduces spontaneous neuronal firing rates, while anodal tDCS has the opposite effect. Accordingly, similar effects have been observed (Nitsche and Paulus, 2000) in humans. Cathodal polarization over the motor cortex can induce motor cortex excitability reductions, while anodal polarization increases motor cortex excitability (Nitsche and Paulus, 2000). Similar to rTMS, these changes last for minutes to hours beyond the end of stimulation, depending on the stimulation parameters.

Non-invasive brain stimulation techniques exert their effects on neuronal excitation through different mechanisms. TMS induces a current that can elicit action potentials in neurons. tDCS induces a polarization that is too weak to elicit action potentials in cortical neurons. However, it effectively modifies the evoked cortical response to afferent stimulation as well as the postsynaptic activity level of cortical neurons, presumably by inducing a shift in intrinsic neuronal excitability (as shown in tDCS studies on animals, Bindman et al., 1962, 1964, 1979; Purpura and McMurtry, 1965). In spite of this difference, it is likely that both techniques induce cerebral plasticity effects that are comparable in many aspects (Ridding and Ziemann, 2010). Both long-term potentiation and its opposite, long-term depression, have also been postulated to explain the persistent effects of non-invasive brain stimulation on cortical activity (Cooke and Bliss, 2006; Thickbroom, 2007; Ziemann and Siebner, 2008).

In sum, these techniques have been shown to induce modifications of cortical plasticity that may outlast the stimulation period itself. Given this potential, there is currently a growing interest in therapeutically applying these methodologies to reduce cognitive deficits in patients with stroke and chronic neurodegenerative diseases.

The potential for inducing behavioral improvement in patients with memory deficits, and the further possibility that these effects may be long-lasting, is intriguing to many researchers and clinicians. Furthermore, the results of these studies could lead to the development of completely new therapeutic approaches (Table 3).

Solé-Padullés et al. (2006) demonstrated a beneficial role of high-frequency rTMS in associative memory among elderly subjects with memory deficits and low performance on neuropsychological memory tests. This study combined rTMS and fMRI to show behavioral improvement in a face-name association memory task following a single session of off-line stimulation over the bilateral PFC that was not evident in the placebo group. This improvement was associated with the recruitment of the right PFC and the bilateral posterior cortices as shown by fMRI (SoléPadullés et al., 2006). Moreover, a recent study by Cotelli et al. (2011a) assessed whether the application of daily high-frequency rTMS to the left parietal area for 2 weeks could lead to significant improvements in memory for face-name associations in an individual with aMCI. The rationale for examining face-name associations was that an early symptom of memory impairment in $\mathrm{AD}$ is a particular problem with forgetting or failing to learn people's names (Greene and Hodges, 1996; Holzer and Warshaw, 2000). A significant improvement was found, providing evidence for a putative role of the left parietal area in associative memory and its enhancement by rTMS (Cotelli et al., 2011a).

With respect to $\mathrm{AD}$ patients, three tDCS studies have been conducted. First, Ferrucci et al. (2008) found that word recognition memory task (WRT) accuracy increased after a single session of anodal tDCS applied bilaterally over temporal-parietal areas in AD patients, while WRT performance worsened after cathodal tDCS. Moreover, in two subsequent studies, Boggio et al. (2009, 2011a) investigated the effects of anodal tDCS on long-term memory performance among AD patients. Boggio et al. (2009) applied a single anodal tDCS session over the left DLPFC or over the left temporal cortex and reported improved recognition memory (visual recognition memory task). Recently, Boggio et al. (2011b) demonstrated that repeated sessions of anodal tDCS applied bilaterally over the temporal area resulted in a performance increase in a group of $\mathrm{AD}$ patients for visual recognition memory tasks. Importantly, this effect was also present at the 4-week follow-up (Boggio et al., 2011b).

In summary, non-invasive brain stimulation techniques may play a role in designing multidimensional models for interventional therapies for individuals with memory impairments. A recent review concluded that stimulation techniques appear safe in $\mathrm{AD}$ patients, but the long-term risks have not been sufficiently evaluated (Freitas et al., 2011). Further studies are needed to identify the optimal responders to specific non-invasive brain stimulation interventions (Boggio et al., 2011b; Guerra et al., 2011; Vallar and Bolognini, 2011). However, these initial studies indicate that, while further randomized, placebo-controlled studies are needed, these interventions appear to have the potential to significantly contribute to the improvement and provision of care for people with $\mathrm{AD}$ and MCI. Moreover, further lines of inquiry should evaluate the functional changes in cortical reactivity and effective connectivity induced by cognitive plasticity as assessed by the coregistration of TMS or $\mathrm{ADCS}$ and EEG, fMRI, DTI, or MEG before, during and after intervention.

\section{CONCLUSION}

In conclusion, the studies described above have shown that nonpharmacological intervention can enhance the effect of ChEI treatment. Generally, these studies compared a combined treatment with pharmacological intervention alone. However, several studies included more than one control condition to verify the improvements induced by the specific cognitive training used (Cotelli et al., 2011c). Moreover, a crucial issue in non-pharmacological rehabilitation is the duration of the induced effects; given the demanding nature of these studies, thus far, only a few have considered long-term follow-up.

Although further controlled studies are needed to demonstrate the efficacy of cognitive training and stimulation interventions, the present review highlights that both of these interventions might be useful in enhancing memory functioning in individuals with 


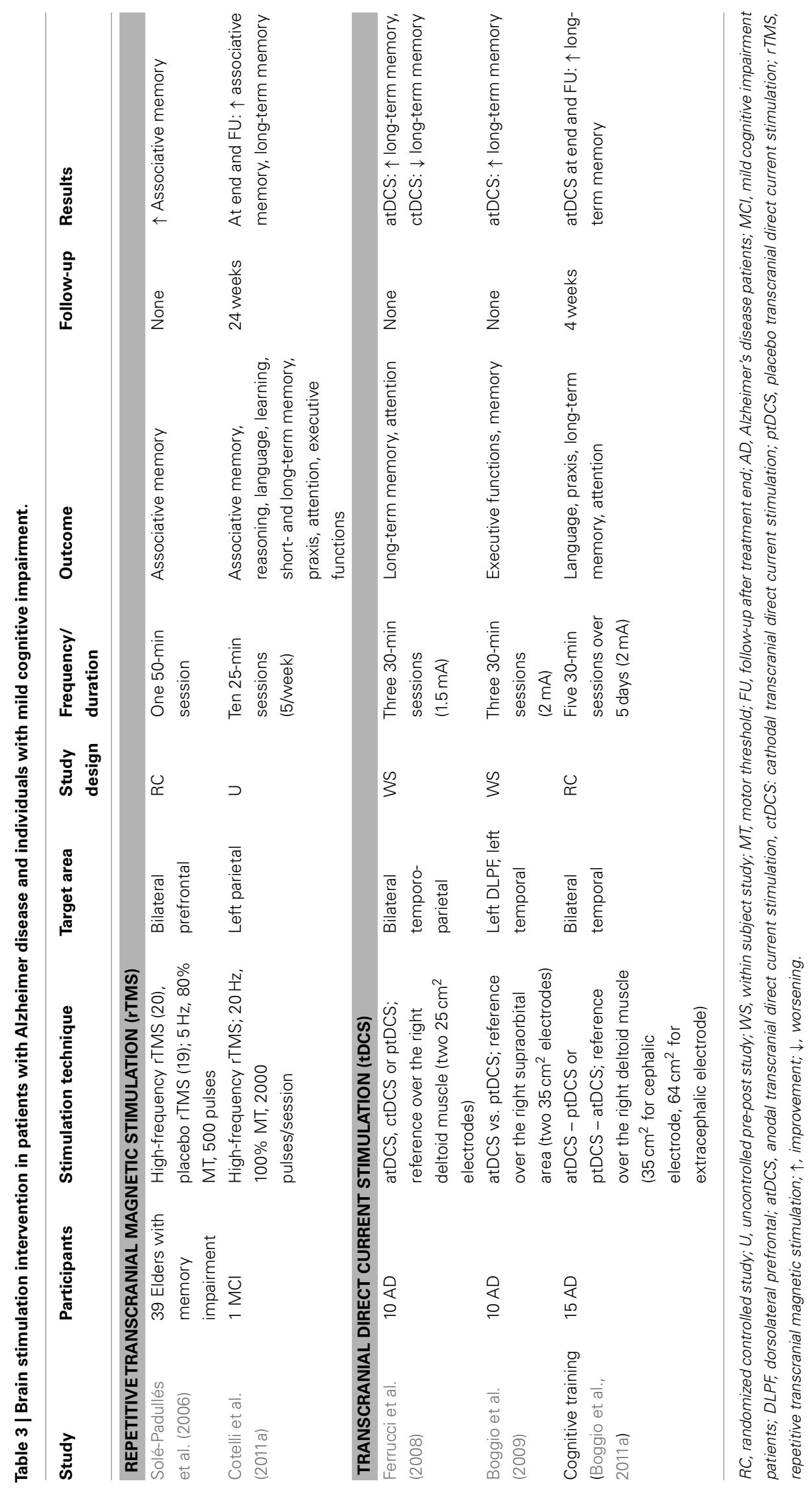


memory disorders. A comprehensive and uniform rehabilitation program should be designed with memory improvement as the primary target. Furthermore, unification of the gains obtained by these two interventions should increase the usefulness of these training protocols among these patients. Accordingly, it is reasonable to suggest that combined treatment paradigms (tDCS or rTMS during cognitive training) may ameliorate the cognitive decline associated with aMCI/AD more effectively than either one

\section{REFERENCES}

Acevedo, A., and Loewenstein, D. A. (2007). Nonpharmacological cognitive interventions in aging and dementia. J. Geriatr. Psychiatry Neurol. 20, 239-249.

Akhtar, S., Moulin, C. J., and Bowie, P. C. (2006). Are people with mild cognitive impairment aware of the benefits of errorless learning? Neuropsychol. Rehabil. 16, 329-346.

Backman, L. (1996). Utilizing compensatory task conditions for episodic memory in Alzheimer's disease. Acta Neurol. Scand. Suppl. 165, 109-113.

Backman, L., Andersson, J. L., Nyberg, L., Winblad, B., Nordberg, A., and Almkvist, O. (1999). Brain regions associated with episodic retrieval in normal aging and Alzheimer's disease. Neurology 52, 1861-1870.

Backman, L., and Dixon, R. A. (1992). Psychological compensation: a theoretical framework. Psychol. Bull. 112, 259-283.

Baddeley, A., and Wilson, B. A. (1994). When implicit learning fails: amnesia and the problem of error elimination. Neuropsychologia 32, 53-68.

Ball, K., Berch, D. B., Helmers, K. F., Jobe, J. B., Leveck, M. D., Marsiske, M., Morris, J. N., Rebok, G. W., Smith, D. M., Tennstedt, S. L., Unverzagt, F. W., and Willis, S. L. (2002). Effects of cognitive training interventions with older adults: a randomized controlled trial. JAMA 288, 2271-2281.

Barker, A. T., Freeston, I. L., Jalinous, R., and Jarratt, J. A. (1987). Magnetic stimulation of the human brain and peripheral nervous system: an introduction and the results of an initial clinical evaluation. Neurosurgery 20 , 100-109.

Barker, A. T., Jalinous, R., and Freeston, I. L. (1985). Non-invasive magnetic stimulation of human motor cortex. Lancet 1, 1106-1107.

Barnes, D. E., Yaffe, K., Belfor, N., Jagust, W. J., DeCarli, C., Reed, B. R., and Kramer, J. H. (2009). Computerbased cognitive training for mild cognitive impairment: results from a pilot randomized, controlled trial.
Alzheimer Dis. Assoc. Disord. 23, 205-210.

Beck, C., Heacock, P., Mercer, S., Thatcher, R., and Sparkman, C. (1988). The impact of cognitive skills remediation training on persons with Alzheimer's disease or mixed dementia. J. Geriatr. Psychiatry 21, 73-88.

Becker, J. T., Mintun, M. A., Aleva, K., Wiseman, M. B., Nichols, T., and DeKosky, S. T. (1996). Compensatory reallocation of brain resources supporting verbal episodic memory in Alzheimer's disease. Neurology 46, 692-700.

Belleville, S., Clement, F., Mellah, S., Gilbert, B., Fontaine, F., and Gauthier, S. (2011). Training-related brain plasticity in subjects at risk of developing Alzheimer's disease. Brain 134, 1623-1634.

Belleville, S., Gilbert, B., Fontaine, F., Gagnon, L., Menard, E., and Gauthier, S. (2006). Improvement of episodic memory in persons with mild cognitive impairment and healthy older adults: evidence from a cognitive intervention program. Dement. Geriatr. Cogn. Disord. 22, 486-499.

Bindman, L. J., Lippold, O. C., and Milne, A. R. (1979). Prolonged changes in excitability of pyramidal tract neurones in the cat: a post-synaptic mechanism. J. Physiol. (Lond.) 286, 457-477.

Bindman, L. J., Lippold, O. C., and Redfearn, J. W. (1962). Long-lasting changes in the level of the electrical activity of the cerebral cortex produced bypolarizing currents. Nature 196, 584-585.

Bindman, L. J., Lippold, O. C., and Redfearn, J. W. (1964). The Action of brief polarizing currents on the cerebral cortex of the rat (1) during current flow and (2) in the production of long-lasting after-effects. $J$. Physiol. (Lond.) 172, 369-382.

Bird, M., and Kinsella, G. (1996). Longterm cued recall of tasks in senile dementia. Psychol. Aging 11, 45-56.

Boggio, P. S., Ferrucci, R., Mameli, F., Martins, D., Martins, O., Vergari, M., Tadini, L., Scarpini, E.,

of these techniques alone. Further studies, based on larger patient samples and including placebo and control conditions, should be conducted to identify the optimal parameters for such a combined treatment protocol.

\section{ACKNOWLEDGMENTS}

This work was supported by a grant from the Alzheimer's Association (NIRG-11-205099).

Fregni, F., and Priori, A. (2011a). Prolonged visual memory enhancement after direct current stimulation in Alzheimer's disease. Brain Stimul. PMID: 21840288. [Epub ahead of print].

Boggio, P. S., Valasek, C. A., Campanha, C., Giglio, A. C., Baptista, N. I., Lapenta, O. M., and Fregni, F. (2011b). Non-invasive brain stimulation to assess and modulate neuroplasticity in Alzheimer's disease. Neuropsychol. Rehabil. 21, 703-716.

Boggio, P. S., Khoury, L. P., Martins, D. C., Martins, O. E., de Macedo, E. C., and Fregni, F. (2009). Temporal cortex direct current stimulation enhances performance on a visual recognition memory task in Alzheimer disease. J. Neurol. Neurosurg. Psychiatr. 80, 444-447.

Buckner, R. L., Wheeler, M. E., and Sheridan, M. A. (2001). Encoding processes during retrieval tasks. $J$. Cogn. Neurosci. 13, 406-415.

Buschert, V., Bokde, A. L., and Hampel, H. (2011). Cognitive intervention in Alzheimer disease. Nat Rev Neurol 6, 508-517.

Cabeza, R. (2002). Hemispheric asymmetry reduction in older adults: the HAROLD model. Psychol. Aging 17, 85-100.

Cabeza, R., Anderson, N. D., Houle, S., Mangels, J. A., and Nyberg, L. (2000). Age-related differences in neural activity during item and temporalorder memory retrieval: a positron emission tomography study. J. Cogn. Neurosci. 12, 197-206.

Cabeza, R., Ciaramelli, E., Olson, I. R., and Moscovitch, M. (2008). The parietal cortex and episodic memory: an attentional account. Nat. Rev. Neurosci. 9, 613-625.

Cabeza, R., Grady, C. L., Nyberg, L., McIntosh, A. R., Tulving, E., Kapur, S., Jennings, J. M., Houle, S., and Craik, F. I. (1997). Age-related differences in neural activity during memory encoding and retrieval: a positron emission tomography study. J. Neurosci. 17, 391-400.

Cabeza, R., Locantore, J. K., and Anderson, N. D. (2003). Lateralization of prefrontal activity during episodic memory retrieval: evidence for the production-monitoring hypothesis. J. Cogn. Neurosci. 15, 249-259.

Cabeza, R., and Nyberg, L. (2003). Functional neuroimaging of memory. Neuropsychologia 41, 241-244.

Cahn-Weiner, D. A., Malloy, P. F., Rebok, G. W., and Ott, B. R. (2003). Results of a randomized placebocontrolled study of memory training for mildly impaired Alzheimer's disease patients. Appl. Neuropsychol. 10, 215-223.

Camp, C. J., Foss, J. W., O'Hanlon, A. M., and Stevens, A. B. (1996). Memory interventions for persons with dementia. Appl. Cogn. Psychol. 10, 193-210.

Camp, C. J., Foss, J. W., Stevens, A. B., Reichard, C. C., McKitrick, L. A., and O’Hanlon, A. M. (1993). Memory training in normal and demented elderly populations: the E-I-E-I-O model. Exp. Aging Res. 19, 277-290.

Camp, C. J., and Stevens, A. B. (1990). Spaced-retrieval: a memory intervention for dementia of the Alzheimer's type. Clin. Gerontol. 10, 58-61.

Chen, R., Classen, J., Gerloff, C., Celnik, P., Wassermann, E. M., Hallett, M., and Cohen, L. G. (1997). Depression of motor cortex excitability by low-frequency transcranial magnetic stimulation. Neurology 48, 1398-1403.

Cherry, K. E., and SimmonsD'Gerolamo, S. S. (2005). Long-term effectiveness of spaced-retrieval memory training for older adults with probable Alzheimer's disease. Exp. Aging Res. 31, 261-289.

Cherry, K. E., Walvoord, A. A., and Hawley, K. S. (2010). Spaced retrieval enhances memory for a nameface-occupation association in older adults with probable Alzheimer's disease. J. Genet. Psychol. 171, 168-181.

Chertkow, H., Nasreddine, Z., Joanette, Y., Drolet, V., Kirk, J., Massoud, F., Belleville, S., and Bergman, $\mathrm{H}$. (2007). Mild cognitive impairment and cognitive impairment, no dementia: part A, concept and diagnosis. Alzheimers Dement. 3, 266-282. 
Cipriani, G., Bianchetti, A., and Trabucchi, M. (2006). Outcomes of a computer-based cognitive rehabilitation program on Alzheimer's disease patients compared with those on patients affected by mild cognitive impairment. Arch. Gerontol. Geriatr. 43, 327-335.

Clare, L., van Paasschen, J., Evans, S. J., Parkinson, C., Woods, R. T., and Linden, D. E. (2009). Goaloriented cognitive rehabilitation for an individual with mild cognitive impairment: behavioural and neuroimaging outcomes. Neurocase 15, 318-331.

Clare, L., and Wilson, B. A. (2004). Memory rehabilitation for people with early-stage dementia: a single case comparison of four errorless learning methods. Z. Gerontopsycho. Psychiatr. 17, 109-117.

Clare, L., Wilson, B. A., Breen, K., and Hodges, J. R. (1999). Errorless learning of face-name associations in early Alzheimer's disease. Neurocase 5, 37-46.

Clare, L., Wilson, B. A., Carter, G., Breen, K., Gosses, A., and Hodges, J. R. (2000). Intervening with everyday memory problems in dementia of Alzheimer type: an errorless learning approach. J. Clin. Exp. Neuropsychol. 22, 132-146.

Clare, L., Wilson, B. A., Carter, G., and Hodges, J. R. (2003a). Cognitive rehabilitation as a component of early intervention in Alzheimer's disease: a single case study. Aging Ment. Health 7, 15-21.

Clare, L., Woods, R. T., Moniz Cook, E. D., Orrell, M., and Spector, A. (2003b). Cognitive rehabilitation and cognitive training for earlystage Alzheimer's disease and vascular dementia. Cochrane Database Syst. Rev. CD003260.

Clare, L., Wilson, B. A., Carter, G., Hodges, J. R., and Adams, M. (2001). Long-term maintenance of treatment gains following a cognitive rehabilitation intervention in early dementia of Alzheimer type: a single case study. Neuropsychol. Rehabil.11, 477-494.

Clare, L., Wilson, B. A., Carter, G., Roth, I., and Hodges, J. R. (2002). Relearning face-name associations in early Alzheimer's disease. Neuropsychology 16, 538-547.

Cooke, S. F., and Bliss, T. V. (2006). Plasticity in the human central nervous system. Brain 129, 1659-1673.

Cotelli, M., Calabria, M., Manenti, R., Rosini, S., Maioli, C., Zanetti, O., and Miniussi, C. (2011a). Brain stimulation improves associative memory in an individual with amnestic mild cognitive impairment. Neurocase. PMID: 21879993. [Epub ahead of print].

Cotelli, M., Fertonani, A., Miozzo, A. Rosini, S., Manenti, R., Padovani, A., Ansaldo, A. I., Cappa, S. F., and Miniussi, C. (2011b). Anomia training and brain stimulation in chronic aphasia. Neuropsychol. Rehabil. 21, 717-741.

Cotelli, M., Manenti, R., and Zanetti, O. (2011c). The Additional Contribution of Combination of Pharmacological Therapy and Cognitive Stimulation in Alzheimer's disease. Review of the Literature. Nonpharmacol. Ther. Dement. 2, 65-73.

Cotelli, M., Calabria, M., and Zanetti, O. (2006). Cognitive rehabilitation in Alzheimer's disease. Aging Clin. Exp. Res. 18, 141-143.

Craik, F. I., Winocur, G., Palmer, H., Binns, M. A., Edwards, M., Bridges, K., Glazer, P., Chavannes, R., and Stuss, D. T. (2007). Cognitive rehabilitation in the elderly: effects on memory. J. Int. Neuropsychol. Soc. 13, 132-142.

Creasey, H., and Rapoport, S. I. (1985). The aging human brain. Ann. Neurol. 17, 2-10.

Creutzfeldt, O. D., Fromm, G. H., and Kapp, H. (1962). Influence of transcortical d-c currents on cortical neuronal activity. Exp. Neurol. 5, 436-452.

Davis, R. N., Massman, P. J., and Doody, R. S. (2001). Cognitive intervention in Alzheimer disease: a randomized placebo-controlled study. Alzheimer Dis. Assoc. Disord. 15, 1-9.

De Vreese, L. P., Neri, M., Fioravanti, M., Belloi, L., and Zanetti, O. (2001). Memory rehabilitation in Alzheimer's disease: a review of progress. Int. J. Geriatr. Psychiatry 16, 794-809.

Dennis, N. A., Hayes, S. M., Prince, S. E., Madden, D. J., Huettel, S. A., and Cabeza, R. (2008). Effects of aging on the neural correlates of successful item and source memory encoding. J. Exp. Psychol. Learn. Mem. Cogn. 34, 791-808.

Dunn, J., and Clare, L. (2007). Learning face-name associations in earlystage dementia: comparing the effects of errorless learning and effortful processing. Neuropsychol. Rehabil. 17, 735-754.

Evans, J. J., Wilson, B. A., Schuri, U., Andrade, J., Baddeley, A., Bruna, O., Canavan, T., Del Sala, S., Green, R., Laaksonen, R., Lorenzi, L., and Taussik, I. (2000). A Comparison of "Errorless" and "Trial-anderror" learning methods for teaching individuals with acquired memory deficits. Neuropsychol. Rehabil. 10, 67-101.

Farina, E., Fioravanti, R., Chiavari, L., Imbornone, E., Alberoni, M., Pomati, S., Pinardi, G., Pignatti, R., and Mariani, C. (2002). Comparing two programs of cognitive training in Alzheimer's disease: a pilot study. Acta Neurol. Scand. 105, 365-371.

Farina, E., Mantovani, F., Fioravanti, R., Pignatti, R., Chiavari, L., Imbornone, E., Olivotto, F., Alberoni, M., Mariani, C., and Nemni, R. (2006). Evaluating two group programmes of cognitive training in mild-tomoderate $\mathrm{AD}$ : is there any difference between a "global" stimulation and a "cognitive-specific" one? Aging Ment. Health 10, 211-218.

Ferrucci, R., Mameli, F., Guidi, I., Mrakic-Sposta, S., Vergari, M., Marceglia, S., Cogiamanian, F., Barbieri, S., Scarpini, E., and Priori, A. (2008). Transcranial direct current stimulation improves recognition memory in Alzheimer disease. Neurology 71, 493-498.

Fletcher, P. C., and Henson, R. N. (2001). Frontal lobes and human memory: insights from functional neuroimaging. Brain 124, 849-881.

Fratiglioni, L., Paillard-Borg, S., and Winblad, B. (2004). An active and socially integrated lifestyle in late life might protect against dementia. Lancet Neurol. 3, 343-353.

Freitas, C., Mondragon-Llorca, H., and Pascual-Leone, A. (2011). Noninvasive brain stimulation in Alzheimer's disease: systematic review and perspectives for the future. Exp. Gerontol. 46, 611-627.

Gauthier, S., Reisberg, B., Zaudig, M. Petersen, R. C., Ritchie, K., Broich, K., Belleville, S., Brodaty, H., Bennett, D., Chertkow, H., Cummings, J. L., de Leon, M., Feldman, H., Ganguli, M., Hampel, H., Scheltens, P., Tierney, M. C., Whitehouse, P., and Winblad, B. (2006). Mild cognitive impairment. Lancet 367 , 1262-1270.

Glisky, E. L. (1992). Computer-assisted instruction for patients with traumatic brain injury: teaching of domain specific knowledge. J. Head Trauma Rehabil. 7, 1-12.

Glisky, E. L., Schacter, D. L., and Tulving, E. (1986). Learning and retention of computer-related vocabulary in memory-impaired patients: method of vanishing cues. J. Clin. Exp. Neuropsychol. 8, 292-312.

Grady, C., and Craik, F. I. (2000). Changes in memory processing with age. Curr. Opin. Neurobiol. 10, 224-231.

Grady, C. L., McIntosh, A. R., Bookstein, F., Horwitz, B., Rapoport, S. I., and Haxby, J. V. (1998). Age-related changes in regional cerebral blood flow during working memory for faces. Neuroimage 8, 409-425.

Grady, C. L., McIntosh, A. R., Horwitz, B., Maisog, J. M., Ungerleider, L. G., Mentis, M. J., Pietrini, P., Schapiro, M. B., and Haxby, J. V. (1995). Agerelated reductions in human recognition memory due to impaired encoding. Science 269, 218-221.

Greene, J. D., Baddeley, A. D., and Hodges, J. R. (1996). Analysis of the episodic memory deficit in early Alzheimer's disease: evidence from the doors and people test. Neuropsychologia 34, 537-551.

Greene, J. D., and Hodges, J. R. (1996). Identification of famous faces and famous names in early Alzheimer's disease. Relationship to anterograde episodic and general semantic memory. Brain 119(Pt 1), 111-128.

Guerra, A., Assenza, F., Bressi, F., Scrascia, F., Del Duca, M., Ursini, F., Vollaro, S., Trotta, L., Tombini, M., Chisari, C., and Ferreri, F. (2011). Transcranial magnetic stimulation studies in Alzheimer's disease. Int. J. Alzheimers Dis. 2011, 263817.

Gunther, V. K., Schafer, P., Holzner, B. J. and Kemmler, G. W. (2003). Longterm improvements in cognitive performance through computer-assisted cognitive training: a pilot study in a residential home for older people. Aging Ment. Health 7, 200-206.

Gutchess, A. H., Welsh, R. C., Hedden, T., Bangert, A., Minear, M., Liu, L. L., and Park, D. C. (2005). Aging and the neural correlates of successful picture encoding: frontal activations compensate for decreased medialtemporal activity. J. Cogn. Neurosci. 17, 84-96.

Hampstead, B. M., Sathian, K., Moore, A. B., Nalisnick, C., and Stringer, A. Y. (2008). Explicit memory training leads to improved memory for facename pairs in patients with mild cognitive impairment: results of a pilot investigation. J. Int. Neuropsychol. Soc. 14, 883-889.

Hampstead, B. M., Stringer, A. Y., Stilla, R. F., Deshpande, G., Hu, X., Moore, A. B., and Sathian, K. (2011). Activation and effective connectivity changes following explicit-memory training for face-name pairs in patients with mild cognitive impairment: a pilot study. Neurorehabil. Neural Repair 25, 210-222.

Haslam, C., Moss, Z., and Hodder, K. (2010). Are two methods better than one? Evaluating the effectiveness of combining errorless learning with vanishing cues. J. Clin. Exp. Neuropsychol. 32, 973-985. 
Hawley, K. S., and Cherry, K. E. (2004). Spaced-retrieval effects on nameface recognition in older adults with probable Alzheimer's disease. Behav. Modif. 28, 276-296.

Hawley, K. S., Cherry, K. E., Boudreaux, E. O., and Jackson, E. M. (2008). A comparison of adjusted spaced retrieval versus a uniform expanded retrieval schedule for learning a name-face association in older adults with probable Alzheimer's disease. J. Clin. Exp. Neuropsychol. 30, 639-649.

Holzer, C., and Warshaw, G. (2000). Clues to early Alzheimer dementia in the outpatient setting. Arch. Fam. Med. 9, 1066-1070.

Hopper, T., Drefs, S. J., Bayles, K. A., Tomoeda, C. K., and Dinu, I. (2010). The effects of modified spacedretrieval training on learning and retention of face-name associations by individuals with dementia. $\mathrm{Neu}$ ropsychol. Rehabil. 20, 81-102.

Hopper, T., Mahendra, N., Kim, E., Azuma, T., Bayles, K. A., Cleary, S. J., and Tomoeda, C. K. (2005). Evidence-based practice recommendations for working with individuals with dementia: spaced-retrieval training. J. Med. Speech Lang. Pathol. 13, xxvii-xxxiv.

Hunkin, N. M., Squires, E. J., Aldrich, F. K., and Parkin, A. J. (1998a). Errorless learning and the acquisition of word processing skills. Neuropsychol. Rehabil. 8, 433-449.

Hunkin, N. M., Squires, E. J., Parkin, A. J., and Tidy, J. A. (1998b). Are the benefits of errorless learning dependent on implicit memory? Neuropsychologia 36, 25-36.

Jean, L., Simard, M., van Reekum, R., and Bergeron, M. E. (2007). Towards a cognitive stimulation program using an errorless learning paradigm in amnestic mild cognitive impairment. Neuropsychiatr. Dis. Treat. 3, 975-985.

Kinsella, G. J., Mullaly, E., Rand, E., Ong, B., Burton, C., Price, S., Phillips, M., and Storey, E. (2009). Early intervention for mild cognitive impairment: a randomised controlled trial. J. Neurol. Neurosurg. Psychiatr. 80, 730-736.

Kircher, T., Weis, S., Leube, D., Freymann, K., Erb, M., Jessen, F., Grodd, W., Heun, R., and Krach, S. (2008). Anterior hippocampus orchestrates successful encoding and retrieval of non-relational memory: an eventrelated fMRI study. Eur. Arch. Psychiatry Clin. Neurosci. 258, 363-372.

Kopelman, M. D. (1985). Multiple memory deficits in Alzheimertype dementia: implications for pharmacotherapy. Psychol. Med. 15, 527-541.

Kurz, A., Pohl, C., Ramsenthaler, M., and Sorg, C. (2009). Cognitive rehabilitation in patients with mild cognitive impairment. Int. J. Geriatr. Psychiatry 24, 163-168.

Laffan, A. J., Metzler-Baddeley, C., Walker, I., and Jones, R. W. (2010). Making errorless learning more active: self-generation in an error free learning context is superior to standard errorless learning of facename associations in people with Alzheimer's disease. Neuropsychol. Rehabil. 20, 197-211.

Landauer, T. K., and Bjork, R. A. (1978). "Optimal rehearsal patterns and name learning," in Pratical Aspects of Memory, ed. M. M. Gruneberg, P. E. Morris, and R. N. Sykes (London: Academic Press), 625-632.

Landi, D., and Rossini, P. M. (2010). Cerebral restorative plasticity from normal ageing to brain disease: a "never ending story." Restor. Neurol. Neurosci. 28, 349-366.

Loewenstein, D. A., Acevedo, A., Czaja, S. J., and Duara, R. (2004). Cognitive rehabilitation of mildly impaired Alzheimer disease patients on cholinesterase inhibitors. Am. J. Geriatr. Psychiatry 12, 395-402.

Londos, E., Boschian, K., Linden, A., Persson, C., Minthon, L., and Lexell, J. (2008). Effects of a goal-oriented rehabilitation program in mild cognitive impairment: a pilot study. Am. J. Alzheimers Dis. Other Demen. 23, 177-183.

Lovden, M., Backman, L., Lindenberger, U., Schaefer, S., and Schmiedek, F. (2010). A theoretical framework for the study of adult cognitive plasticity. Psychol. Bull. 136, 659-676.

Maeda, F., Keenan, J. P., Tormos, J. M., Topka, H., and Pascual-Leone, A. (2000). Modulation of corticospinal excitability by repetitive transcranial magnetic stimulation. Clin. Neurophysiol. 111, 800-805.

Manenti, R., Cotelli, M., Calabria, M., Maioli, C., and Miniussi, C. (2010a). The role of the dorsolateral prefrontal cortex in retrieval from longterm memory depends on strategies: a repetitive transcranial magnetic stimulation study. Neuroscience 166, 501-507.

Manenti, R., Tettamanti, M., Cotelli, M., Miniussi, C., and Cappa, S. F. (2010b). The neural bases of word encoding and retrieval: a fMRIguided transcranial magnetic stimulation study. Brain Topogr. 22, 318-332.
Manenti, R., Cotelli, M., and Miniussi, C. (2011). Successful physiological aging and episodic memory: a brain stimulation study. Behav. Brain Res. 216, 153-158.

McKenna, P., and Gerhand, S. (2002). Preserved semantic learning in an amnesic patient. Cortex 38, 37-58.

Metzler-Baddeley, C., and Snowden, J. S. (2005). Brief report: errorless versus errorful learning as a memory rehabilitation approach in Alzheimer's disease. J. Clin. Exp. Neuropsychol. 27, 1070-1079.

Miniussi, C., Cappa, S. F., Cohen, L. G., Floel, A., Fregni, F., Nitsche, M. A., Oliveri, M., Pascual-Leone, A., Paulus, W., Priori, A., and Walsh, V. (2008). Efficacy of repetitive transcranial magnetic stimulation/transcranial direct current stimulation in cognitive neurorehabilitation. Brain Stimul. 1, 326-336.

Miniussi, C., and Rossini, P. M. (2011). Transcranial magnetic stimulation in cognitive rehabilitation. Neuropsychol. Rehabil. 21, 579-601.

Miniussi, C., and Vallar, G. (2011). Brain stimulation and behavioural cognitive rehabilitation: a new tool for neurorehabilitation? Neuropsychol. Rehabil. 21, 553-559.

Nitsche, M. A., Cohen, L. G., Wassermann, E. M., Priori, A., Lang, N., Antal, A., Paulus, W., Hummel, F. C., Boggio, P. S., Fregni, F., and PascualLeone, A. (2008). Transcranial direct current stimulation: state of the art 2008. Brain Stimul. 1, 206-223.

Nitsche, M. A., and Paulus, W. (2000). Excitability changes induced in the human motor cortex by weak transcranial direct current stimulation. $J$. Physiol. (Lond.) 527(Pt 3), 633-639.

Noack, H., Lovden, M., Schmiedek, F., and Lindenberger, U. (2009). Cognitive plasticity in adulthood and old age: gauging the generality of cognitive intervention effects. Restor Neurol. Neurosci. 27, 435-453.

Nyberg, L., Sandblom, J., Jones, S., Neely, A. S., Petersson, K. M., Ingvar, M., and Backman, L. (2003). Neural correlates of training-related memory improvement in adulthood and aging. Proc. Natl. Acad. Sci. U.S.A. 100, 13728-13733.

Olazaran, J., Muniz, R., Reisberg, B., Pena-Casanova, J., del Ser, T., CruzJentoft, A. J., Serrano, P., Navarro, E., Garcia de la Rocha, M. L., Frank, A., Galiano, M., Fernandez-Bullido, Y., Serra, J. A., Gonzalez-Salvador, M. T., and Sevilla, C. (2004). Benefits of cognitive-motor intervention in MCI and mild to moderate Alzheimer disease. Neurology 63, 2348-2353.
Olazaran, J., Reisberg, B., Clare, L., Cruz, I., Pena-Casanova, J., Del Ser, T., Woods, B., Beck, C., Auer, S., Lai, C., Spector, A., Fazio, S., Bond, J., Kivipelto, M., Brodaty, H., Rojo, J. M., Collins, H., Teri, L., Mittelman, M., Orrell, M., Feldman, H. H., and Muniz, R. (2010). Nonpharmacological therapies in Alzheimer's disease: a systematic review of efficacy. Dement. Geriatr. Cogn. Disord. 30, 161-178.

Onder, G., Zanetti, O., Giacobini, E., Frisoni, G. B., Bartorelli, L., Carbone, G., Lambertucci, P., Silveri, M. C., and Bernabei, R. (2005). Reality orientation therapy combined with cholinesterase inhibitors in Alzheimer's disease: randomised controlled trial. Br. J. Psychiatry 187, 450-455.

Parkin, A. J., Hunkin, N. M., and Squires, E. J. (1998). Unlearning John major: the use of errorless learning in the reacquisition of proper names following herpes simplex encephalitis. Cogn. Neuropsychol. 15, 361-375.

Pascual-Leone, A., Valls-Sole, J., Wassermann, E. M., and Hallett, M. (1994) Responses to rapid-rate transcranial magnetic stimulation of the human motor cortex. Brain $117(\mathrm{Pt}$ 4), 847-858.

Perry, R. J., and Hodges, J. R. (1996). Spectrum of memory dysfunction in degenerative disease. Curr. Opin. Neurol. 9, 281-285.

Petersen, R. C. (2004). Mild cognitive impairment as a diagnostic entity. $J$. Intern. Med. 256, 183-194.

Petersen, R. C., Smith, G. E., Waring, S. C., Ivnik, R. J., Tangalos, E. G. and Kokmen, E. (1999). Mild cognitive impairment: clinical characterization and outcome. Arch. Neurol. 56, 303-308.

Priori, A. (2003). Brain polarization in humans: a reappraisal of an old too for prolonged non-invasive modulation of brain excitability. Clin. Neurophysiol. 114, 589-595.

Purpura, D. P., and McMurtry, J. G. (1965). Intracellular activities and evoked potential changes during polarization of motor cortex. J. Neurophysiol. 28, 166-185.

Rapp, S., Brenes, G., and Marsh, A. P. (2002). Memory enhancement training for older adults with mild cognitive impairment: a preliminary study. Aging Ment. Health 6, 5-11.

Rasmusson, D. X., Rebok, G. W., Bylsma, F. W., and Brandt, J. (1999). Effects of three types of memory training in normal elderly. Aging Neuropsychol. Cogn. 6, 56-66. 
Ridding, M. C., and Ziemann, U. (2010). Determinants of the induction of cortical plasticity by noninvasive brain stimulation in healthy subjects. J. Physiol. (Lond.) 588, 2291-2304.

Rosen, A. C., Prull, M. W., O’Hara, R., Race, E. A., Desmond, J. E., Glover, G. H., Yesavage, J. A., and Gabrieli, J. D. (2002). Variable effects of aging on frontal lobe contributions to memory. Neuroreport 13, 2425-2428.

Rossi, S., Cappa, S. F., Babiloni, C., Pasqualetti, P., Miniussi, C., Carducci, F., Babiloni, F., and Rossini, P. M. (2001). Prefrontal [correction of Prefontal] cortex in long-term memory: an "interference" approach using magnetic stimulation. Nat. Neurosci. 4, 948-952.

Rossi, S., Hallett, M., Rossini, P. M., and Pascual-Leone, A. (2009). Safety, ethical considerations, and application guidelines for the use of transcranial magnetic stimulation in clinical practice and research. Clin. Neurophysiol. 120, 2008-2039.

Rossi, S., Miniussi, C., Pasqualetti, P., Babiloni, C., Rossini, P. M., and Cappa, S. F. (2004). Agerelated functional changes of prefrontal cortex in long-term memory: a repetitive transcranial magnetic stimulation study. J. Neurosci. 24, 7939-7944.

Rossi, S., Pasqualetti, P., Zito, G., Vecchio, F., Cappa, S. F., Miniussi, C., Babiloni, C., and Rossini, P. M. (2006). Prefrontal and parietal cortex in human episodic memory: an interference study by repetitive transcranial magnetic stimulation. Eur. J. Neurosci. 23, 793-800.

Rozzini, L., Costardi, D., Chilovi, B. V., Franzoni, S., Trabucchi, M., and Padovani, A. (2007). Efficacy of cognitive rehabilitation in patients with mild cognitive impairment treated with cholinesterase inhibitors. Int. J. Geriatr. Psychiatry 22, 356-360.

Rugg, M. D., and Wilding, E. L. (2000). Retrieval processing and episodic memory. Trends Cogn. Sci. (Regul. Ed.) 4, 108-115.

Salthouse, T. A. (2006). Mental exercise and mental aging. Perspect. Psychol. Sci. 1, 68-87.

Sandrini, M., Cappa, S. F., Rossi, S., Rossini, P. M., and Miniussi, C. (2003). The role of prefrontal cortex in verbal episodic memory: rTMS evidence. J. Cogn. Neurosci. 15, 855-861.

Schacter, D. L., Savage, C. R., Alpert, N. M., Rauch, S. L., and Albert, M. S. (1996). The role of hippocampus and frontal cortex in age-related memory changes: a PET study. Neuroreport 7, 1165-1169.

Schneider, L. S. (2005). Mild cognitive impairment. Am. J. Geriatr. Psychiatry 13, 629-632.

Shaywitz, S. E., Shaywitz, B. A., Fulbright, R. K., Skudlarski, P., Mencl, W. E., Constable, R. T., Pugh, K. R., Holahan, J. M., Marchione, K. E., Fletcher, J. M., Lyon, G. R., and Gore, J. C. (2003). Neural systems for compensation and persistence: young adult outcome of childhood reading disability. Biol. Psychiatry $54,25-33$.

Simons, J. S., and Spiers, H. J. (2003). Prefrontal and medial temporal lobe interactions in longterm memory. Nat. Rev. Neurosci. 4 , 637-648.

Smith, G. E., Housen, P., Yaffe, K., Ruff, R., Kennison, R. F., Mahncke, H. W., and Zelinski, E. M. (2009). A cognitive training program based on principles of brain plasticity: results from the Improvement in Memory with Plasticity-based Adaptive Cognitive Training (IMPACT) study. J. Am. Geriatr. Soc. 57, 594-603.

Solé-Padullés, C., Bartres-Faz, D. Junque, C., Clemente, I. C., Molinuevo, J. L., Bargallo, N., Sanchez-Aldeguer, J., Bosch, B., Falcon, C., and Valls-Sole, J. (2006). Repetitive transcranial magnetic stimulation effects on brain function and cognition among elders with memory dysfunction. A randomized sham-controlled study. Cereb. Cortex 16, 1487-1493.

Souchay, C., Moulin, C. J., Isingrini, M., and Conway, M. A. (2008). Rehearsal strategy use in Alzheimer's disease. Cogn. Neuropsychol. 25, 783-797.

Squires, E. J., Hunkin, N. M., and Parkin, A. J. (1997). Errorless learning of novel associations in amnesia. $\mathrm{Neu}$ ropsychologia 35, 1103-1111.

Stern, Y. (2002). What is cognitive reserve? Theory and research application of the reserve concept. J. Int. Neuropsychol. Soc. 8, 448-460.

Stern, Y. (2006). Cognitive reserve and Alzheimer disease. Alzheimer Dis. Assoc. Disord. 20, S69-S74.

Stern, Y., Habeck, C., Moeller, J., Scarmeas, N., Anderson, K. E., Hilton, H. J., Flynn, J., Sackeim, H., and van Heertum, R. (2005). Brain networks associated with cognitive reserve in healthy young and old adults. Cereb. Cortex 15, 394-402.

Stott, J., and Spector, A. (2011). A review of the effectiveness of memory interventions in mild cognitive impairment (MCI). Int. Psychogeriatr. 23, 526-538.

Strangman, G., O’Neil-Pirozzi, T. M., Burke, D., Cristina, D., Goldstein, R., Rauch, S. L., Savage, C. R., and Glenn, M. B. (2005). Functional neuroimaging and cognitive rehabilitation for people with traumatic brain injury. Am. J. Phys. Med. Rehabil. 84, 62-75.

Tailby, R., and Haslam, C. (2003). An investigation of errorless learning in memory-impaired patients: improving the technique and clarifying theory. Neuropsychologia 41, 1230-1240

Talassi, E., Guerreschi, M., Feriani, M., Fedi, V., Bianchetti, A., and Trabucchi, M. (2007). Effectiveness of a cognitive rehabilitation program in mild dementia (MD) and mild cognitive impairment (MCI): a case control study. Arch. Gerontol. Geriatr. 44(Suppl. 1), 391-399.

Tardif, S., and Simard, M. (2011). Cognitive stimulation programs in healthy elderly: a review. Int. J. Alzheimers Dis. 2011, 378934.

Thickbroom, G. W. (2007). Transcranial magnetic stimulation and synaptic plasticity: experimental framework and human models. Exp. Brain Res. 180, 583-593.

Thom, J. M., and Clare, L. (2011). Rationale for combined exercise and cognition-focused interventions to improve functional independence in people with dementia. Gerontology 57, 265-275.

Troyer, A. K., Murphy, K. J., Anderson, N. D., Moscovitch, M., and Craik, F. I. (2008). Changing everyday memory behaviour in amnestic mild cognitive impairment: a randomised controlled trial. Neuropsychol. Rehabil. 18 65-88.

Tulving, E. (1983). Elements of Episodic Memory. London: Oxford University Press.

Tulving, E., Kapur, S., Craik, F I., Moscovitch, M., and Houle, S. (1994). Hemispheric encoding/retrieval asymmetry in episodic memory: positron emission tomography findings. Proc. Natl. Acad. Sci. U.S.A. 91, 1989-1991.

Valenzuela, M., and Sachdev, P. (2009). Can cognitive exercise prevent the onset of dementia? Systematic review of randomized clinical trials with longitudinal followup. Am. J. Geriatr. Psychiatry 17, 179-187.

Valenzuela, M. J., and Sachdev, P. (2006). Brain reserve and dementia: a systematic review. Psychol. Med. 36, 441-454.
Vallar, G., and Bolognini, N. (2011). Behavioural facilitation following brain stimulation. Implications for neurorehabilitation. Neuropsychol. Rehabil. 21, 618-649.

Visser, P. J., Kester, A., Jolles, J., and Verhey, F. (2006). Ten-year risk of dementia in subjects with mild cognitive impairment. Neurology 67, 1201-1207.

Wagner, A. D., Poldrack, R. A., Eldridge, L. L., Desmond, J. E., Glover, G. H., and Gabrieli, J. D. (1998). Materialspecific lateralization of prefrontal activation during episodic encoding and retrieval. Neuroreport 9, 3711-3717.

Warburton, E., Price, C. J., Swinburn, K., and Wise, R. J. (1999). Mechanisms of recovery from aphasia: evidence from positron emission tomography studies. J. Neurol. Neurosurg. Psychiatr. 66, 155-161.

Wassermann, E. M., Epstein, C., Ziemann, U., Walsh, V., Paus, T., and Lisanby, S. (2008a). Handbook of Tanscranial Stimulation. Oxford: Oxford University press.

Wassermann, E. M., Epstein, C., Ziemann, U., Walsh, V., Paus, T., and Lisanby, S. (2008b). Oxford Handbook of Transcranial Stimulation.

Wenisch, E., Cantegreil-Kallen, I., De Rotrou, J., Garrigue, P., Moulin, F., Batouche, F., Richard, A., De Sant'Anna, M., and Rigaud, A. S. (2007). Cognitive stimulation intervention for elders with mild $\operatorname{cog}$ nitive impairment compared with normal aged subjects: preliminary results. Aging Clin. Exp. Res. 19, 316-322.

Werheid, K., and Clare, L. (2007). Are faces special in Alzheimer's disease? Cognitive conceptualisation, neural correlates, and diagnostic relevance of impaired memory for faces and names. Cortex 43 , 898-906.

Whitehouse, P., and Brodaty, H. (2006). Mild cognitive impairment. Lancet 367, 1979.

Whitehouse, P. J. (2007). Mild cognitive impairment - a confused concept? Nat. Clin. Pract. Neurol. 3, 62-63.

Willis, S. L., and Schaie, K. W. (1986). Training the elderly on the ability factors of spatial orientation and inductive reasoning. Psychol. Aging 1, 239-247.

Willis, S. L., Tennstedt, S. L., Marsiske, M., Ball, K., Elias, J., Koepke, K. M., Morris, J. N., Rebok, G. W. Unverzagt, F. W., Stoddard, A. M., and Wright, E. (2006). Longterm effects of cognitive training on everyday functional outcomes 
in older adults. JAMA 296, 2805-2814.

Wilson, B. A., Baddeley, A., Evans, J., and Shiel, A. (1994). Errorless learning in the rehabilitation of memory impaired people. Neuropsychol. Rehabil. 4, 307-326.

Winter, J., and Hunkin, N. M. (1999). Re-learning in Alzheimer's disease. Int. J. Geriatr. Psychiatry 14, 988-990.

Woodard, J. L., Grafton, S. T., Votaw, J. R., Green, R. C., Dobraski, M. E., and Hoffman, J. M. (1998). Compensatory recruitment of neural resources during overt rehearsal of word lists in Alzheimer's disease. Neuropsychology 12, 491-504.

Zanetti, O., Bianchetti, A., and Trabucchi, M. (1998). Treatment of Alzheimer's disease. Am. J. Psychiatry 155, 1461.

Zanetti, O., Oriani, M., Geroldi, C., Binetti, G., Frisoni, G. B., Di Giovanni, G., and De Vreese, L. P. (2002). Predictors of cognitive improvement after reality orientation in Alzheimer's disease. Age Ageing 31, 193-196.

Zanetti, O., Zanieri, G., Di Giovanni, G., De Vreese, L., Pezzini, A., Metitieri, T., and Trabucchi, M. (2001). Effectiveness of procedural memory stimulation in mild Alzheimer's disease patients: a controlled study. Neuropsychol. Rehabil. 11, 263-272.

Zehnder, F., Martin, M., Altgassen, M., and Clare, L. (2009). Memory training effects in old age as markers of plasticity: a metaanalysis. Restor. Neurol. Neurosci. 27, 507-520.

Zelinski, E. M., Spina, L. M., Yaffe, K., Ruff, R., Kennison, R. F., Mahncke, H. W., and Smith, G. E. (2011). Improvement in memory with plasticity-based adaptive cognitive training: results of the 3-month follow-up. J. Am. Geriatr. Soc. 59, 258-265.

Ziemann, U., and Siebner, H. R. (2008). Modifying motor learning through gating and homeostatic metaplasticity. Brain Stimul. 1, 60-66.

Conflict of Interest Statement: The authors declare that the research was conducted in the absence of any commercial or financial relationships that could be construed as a potential conflict of interest.

Received: 29 November 2011; accepted: 23 February 2012; published online: 09 March 2012.

Citation: Cotelli M, Manenti R, Zanetti $O$ and Miniussi C (2012) Nonpharmacological intervention for memory decline. Front. Hum. Neurosci. 6:46. doi: 10.3389/fnhum.2012.00046

Copyright (c) 2012 Cotelli, Manenti, Zanetti and Miniussi. This is an openaccess article distributed under the terms of the Creative Commons Attribution Non Commercial License, which permits non-commercial use, distribution, and reproduction in other forums, provided the original authors and source are credited. 